Este trabajo ha obtenido un Accésit del Premio Estudios Financieros 2018 en la modalidad de Educación y Nuevas Tecnologías. El jurado ha estado compuesto por: don Alfonso Aguiló Pastrana, doña Milagros Antón López, don Fernando Checa García, don Ángel de Miguel Casas, doña Laura Rayón Rumayor y don Javier Manuel Valle López. (Los trabajos se presentan con seudónimo y la selección se efectúa garantizando el anonimato de los autores)

\title{
Cómo hacer del Derecho Constitucional una materia amigable con la complicidad de la sociedad
}

\section{Extracto:}

En este estudio presentamos una metodología docente que se lleva aplicando 11 años sobre un colectivo de casi 1.500 estudiantes de Derecho Constitucional y que ha sido pensada para despertar la motivación y el interés. En ella, el alumno busca la implicación de instituciones públicas (Administración, Gobierno, políticos, etc.) mediante su participación directa y personal en el proceso de aprendizaje a través de la presencia virtual en clase. Los resultados obtenidos con algunas actividades se han dado a conocer en las Aulas de la Tercera Edad. Una simbiosis que enriquece y amplía el eco social de la docencia universitaria. En toda la metodología se ha puesto especial atención en la educación en valores para formar a personas y a ciudadanos.

Palabras clave: Derecho Constitucional, motivación, participación, instituciones públicas, educar en valores.

\footnotetext{
${ }^{1}$ A. Carreras Casanovas, profesor de Derecho Constitucional en la Universitat Rovira i Virgili (URV) de Tarragona.
} 


\section{How to make}

\section{Constitutional Law a friendly matter with the complicity of the society}

\section{Abstract:}

Presentation of a teaching methodology whose objective is to arouse motivation and interest. One thousand five hundred Constitutional Law students were analyzed over a period of 11 years. The students were directly and personally involved with governmental institutions, such as Administration, Government and politicians, in order to make the last ones engage in the learning process and virtually presence at class. Some of these activities were presented afterwards in Elderly People Lessons. This is a symbiosis that enriches and expands the social impact of teaching at the university. Throughout the methodology, special attention was paid to educational values to train people and citizens.

Keywords: Constitutional Law, motivation, participation, public institutions, educating in values.

\section{[...] se ha buscado la complicidad de la sociedad como soporte esencial del aprendizaje, implicando a las instituciones (Administración pública, Gobierno, políticos, etc.) mediante su colaboración directa con los estudiantes y su presencia virtual en la clase}

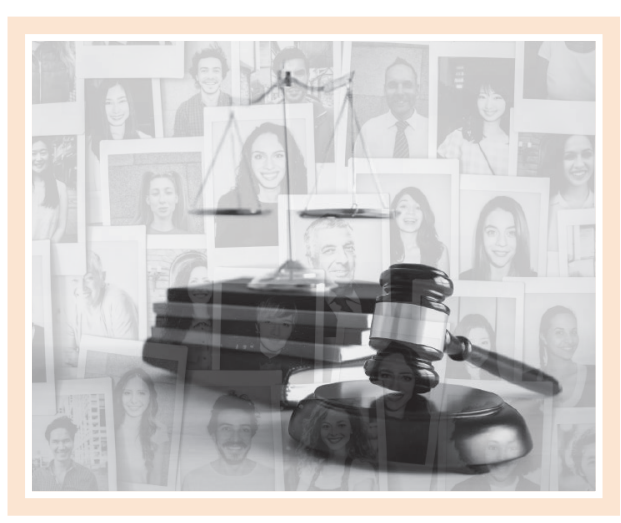

\section{MOTIVACIÓN Y JUSTIFICACIÓN}

En este estudio presentamos una experiencia docente que ha sido aplicada durante 11 años sobre un colectivo de casi 1.500 alumnos de Derecho Constitucional (en la asignatura Ordenamiento Jurídico y Sistema Político [6 créditos-troncal], impartida en el primer curso de los grados de Periodismo, Comunicación Audiovisual y Publicidad y Relaciones Públicas de la Facultad de Letras de la URV de Tarragona, y en la asignatura Elementos de Derecho Constitucional [ 6 créditos-troncal], impartida en el primer curso del grado de Relaciones Laborales y Ocupación de la Facultad de Ciencias Jurídicas de la URV de Tarragona).

Dado que se trata de una materia que para la mayoría de los alumnos de primer curso de las diferentes enseñanzas mencionadas no presenta de entrada un especial interés de aprendizaje, lo que favorece un alto grado de absentismo y la falta de atención en clase, se ha creado una metodología docente pensada para despertar la motivación, el interés y la participación, hasta el punto de que se ha conseguido que el alumno considere esta materia como una de las más interesantes y estimuladoras del curso, según las propias manifestaciones de los estudiantes, alcanzando la consecución de un amplio abanico de competencias específicas, transversales y nucleares.

Para conseguir estos objetivos se ha buscado la complicidad de la sociedad como soporte esencial del 
aprendizaje, implicando a las instituciones (Administración pública, Gobierno, políticos, etc.) mediante su colaboración directa con los estudiantes y su presencia virtual en la clase. Por otra parte, los resultados obtenidos de algunas actividades han servido para darlos a conocer en las Aulas de la Tercera Edad. En esta metodología se ha puesto especial énfasis en la educación en valores.

La bondad del método ha sido constatada estadísticamente con unos resultados altamente alentadores: se ha superado con creces el centenar de instituciones y personalidades relevantes que han participado, se ha hecho extensivo a las Aulas de la Tercera Edad en una quincena de localidades, los estudiantes han valorado muy positivamente el plan de trabajo y se ha visualizado en diversos congresos nacionales e internacionales y en varias jornadas.

Pero la consecución de estos resultados ha sido posible gracias a la motivación; es decir, a la motivación del propio docente, que ha intentado dar lo mejor de sí mismo en cada clase, año tras año, con ilusión y entrega. Motivación que se contagia a los alumnos y que consigue, día a día, que fluya una química positiva entre el docente y los estudiantes, creando un vínculo intangible de complicidad participativa y docente. La clave de esta metodología es la imaginación, mucha motivación y la empatía del docente.

\section{La clave de esta metodología es la imaginación, mucha motivación y la empatía del docente}

\section{METODOLOGÍA DOCENTE. PLAN DE TRABAJO}

Con el fin de replantear el sistema tradicional de las clases magistrales y de prácticas, se ha creado una nueva metodología docente, fijando de entrada una serie de competencias u objetivos y un plan de trabajo adaptado a estas competencias.

\subsection{Cursos académicos en los que se ha impartido esta metodología}

El plan de trabajo se puso en marcha durante el curso académico 2007-2008 en el grado de Relaciones Laborales y Ocupación, aplicándose posteriormente a otras enseñanzas, como se puede ver en la tabla 1.

Tabla 1. Curso académico, facultad, grado y asignatura sobre los que se ha impartido esta metodología

\begin{tabular}{|c|c|c|c|c|}
\hline Año & Curso & Facultad & Grado & Nombre de la asignatura \\
\hline 1 & $2007-2008$ & Ciencias Jurídicas ... & Relaciones Laborales y Ocupación & Instituciones de Derecho Constitucional \\
\hline 2 & 2008-2009 & Ciencias Jurídicas ... & Relaciones Laborales y Ocupación & Instituciones de Derecho Constitucional \\
\hline 3 & $2009-2010$ & $\begin{array}{l}\text { Ciencias Jurídicas ... } \\
\text { Letras ........................ }\end{array}$ & $\begin{array}{l}\text { Relaciones Laborales y Ocupación } \\
\text { Periodismo, Comunicación Audiovisual } \\
\text { y Publicidad y Relaciones Públicas }\end{array}$ & $\begin{array}{l}\text { Elementos de Derecho Constitucional } \\
\text { Ordenamiento Jurídico y Sistema Político }\end{array}$ \\
\hline 4 & $2010-2011$ & Ciencias Jurídicas ... & Relaciones Laborales y Ocupación & Elementos de Derecho Constitucional \\
\hline 5 & $2011-2012$ & Ciencias Jurídicas ... & Relaciones Laborales y Ocupación & Elementos de Derecho Constitucional \\
\hline 6 & 2012-2013 & Ciencias Jurídicas ... & Relaciones Laborales y Ocupación & Elementos de Derecho Constitucional \\
\hline 7 & 2013-2014 & Ciencias Jurídicas ... & Relaciones Laborales y Ocupación & Elementos de Derecho Constitucional \\
\hline
\end{tabular}




\begin{tabular}{|c|c|c|c|c|}
\hline Año & Curso & Facultad & Grado & Nombre de la asignatura \\
\hline \multicolumn{5}{|l|}{$\ldots / \ldots$} \\
\hline 8 & 2014-2015 & Ciencias Jurídicas .. & Relaciones Laborales y Ocupación & Elementos de Derecho Constitucional \\
\hline 9 & $2015-2016$ & $\begin{array}{l}\text { Ciencias Jurídicas .. } \\
\text { Letras ...................... }\end{array}$ & $\begin{array}{l}\text { Relaciones Laborales y Ocupación } \\
\text { Periodismo, Comunicación Audiovisual } \\
\text { y Publicidad y Relaciones Públicas }\end{array}$ & $\begin{array}{l}\text { Elementos de Derecho Constitucional } \\
\text { Ordenamiento Jurídico y Sistema Político }\end{array}$ \\
\hline 10 & $2016-2017$ & $\begin{array}{l}\text { Ciencias Jurídicas .. } \\
\text { Letras ...................... }\end{array}$ & $\begin{array}{l}\text { Relaciones Laborales y Ocupación } \\
\text { Periodismo, Comunicación Audiovisual } \\
\text { y Publicidad y Relaciones Públicas }\end{array}$ & $\begin{array}{l}\text { Elementos de Derecho Constitucional } \\
\text { Ordenamiento Jurídico y Sistema Político }\end{array}$ \\
\hline 11 & $2017-2018$ & $\begin{array}{l}\text { Ciencias Jurídicas .. } \\
\text { Letras ..................... }\end{array}$ & $\begin{array}{l}\text { Relaciones Laborales y Ocupación } \\
\text { Periodismo, Comunicación Audiovisual } \\
\text { y Publicidad y Relaciones Públicas }\end{array}$ & $\begin{array}{l}\text { Elementos de Derecho Constitucional } \\
\text { Ordenamiento Jurídico y Sistema Político }\end{array}$ \\
\hline
\end{tabular}

Fuente: elaboración propia.

El conjunto de alumnos de los grados de Relaciones Laborales y Ocupación, Periodismo, Comunicación Audiovisual y Publicidad y Relaciones Públicas a los que se les ha aplicado esta nueva metodología docente ha sido en total de 1.495 , desglosados como se indica en la tabla 2.

\begin{tabular}{|c|c|c|c|c|c|}
\hline \multirow[b]{3}{*}{ Curso } & \multicolumn{4}{|c|}{ Grados } & \multirow[b]{3}{*}{ Total } \\
\hline & \multicolumn{2}{|c|}{ Relaciones Laborales y Ocupación } & \multicolumn{2}{|c|}{$\begin{array}{l}\text { Periodismo, Comunicación Audiovisual y } \\
\text { Publicidad y Relaciones Públicas }\end{array}$} & \\
\hline & Mañana & Tarde & Mañana & Tarde & \\
\hline 2007-2008 & 39 & 28 & & & 67 \\
\hline 2008-2009 & & 44 & & & 44 \\
\hline 2009-2010 & & 47 & 33 & 67 & 147 \\
\hline 2010-2011 & 77 & 55 & & & 132 \\
\hline 2011-2012 & 70 & 54 & & & 124 \\
\hline 2012-2013 & 87 & 27 & & & 114 \\
\hline 2013-2014 & 68 & 22 & & & 90 \\
\hline 2014-2015 & 60 & & 82 & 61 & 203 \\
\hline 2015-2016 & 62 & & 68 & 58 & 188 \\
\hline & & & & &. .1 \\
\hline
\end{tabular}


Tabla 2. Número de estudiantes a los que se les ha impartido esta metodología (cont.)

\begin{tabular}{|l|c|c|c|c|c|}
\hline \multicolumn{2}{|c|}{ Grados } \\
\hline \multicolumn{2}{|c|}{ Relaciones Laborales y Ocupación } & $\begin{array}{r}\text { Periodismo, Comunicación Audiovisual y } \\
\text { Publicidad y Relaciones Públicas }\end{array}$ & Total \\
\hline \multicolumn{1}{|c|}{ Curso } & Mañana & Tarde & Mañana & 191 \\
\hline$\ldots$ & & & 76 & 44 & 195 \\
\hline $2016-2017$ & 71 & 66 & 59 & 70 & 1.495 \\
\hline
\end{tabular}

Fuente: elaboración propia en función de la calificación de las actas.

\subsection{Competencias marcadas}

Para poder conseguir las competencias que a continuación se explican, contextualizadas dentro del modelo docente de la URV, ha sido básico que el alumno sienta interés por la materia, de tal manera que muchas de estas competencias han tenido una doble finalidad: las propias de las competencias y la estrategia para hacer amigable la materia. El logro de estas competencias a través de esta metodología ha contribuido notablemente a la mejora de la calidad en la docencia.

A) Competencias específicas (objetivos de contenidos competenciales)

- Asimilación de los contenidos de la materia impartida (Derecho Constitucional). No olvidemos que es necesario que el alumno aprenda los contenidos de la materia, y esto se debe hacer del modo en que los asimile mejor, transformando la asignatura en una materia motivadora y agradable. A pesar de todo esto, no se ha descuidado la rigidez del contenido, ni el rigor de las explicaciones, así como tampoco ha disminuido el trabajo. Es más, se ha incrementado notablemente.

- Argumentar y razonar jurídicamente los contenidos alcanzados dentro del contexto de la realidad político-social que nos rodea. Dado que el Derecho Constitucional es una materia de trascen- dencia político-social, hemos tenido que encontrar los contenidos que mejor se pudieran aplicar a la realidad actual, para que el alumno se diera cuenta del trasfondo constitucional de los acontecimientos que nos rodean y fuera capaz de analizar los hechos con profundidad jurídica.

- Aplicación de los contenidos en el ámbito laboral. Enseñar el funcionamiento de las herramientas necesarias para saber utilizarlas en el mundo laboral.

B) Competencias transversales (objetivos de aprendizaje)

- Despertar el interés por una materia, de entrada poco estimulante. El componente altamente teórico de la materia Derecho Constitucional con frecuencia se encuentra alejado de la realidad que vive el alumno de primer curso, a la vez que la parte práctica de la materia se presenta en una casuística generalmente muy especializada, lo que es habitual en muchas materias de diversas enseñanzas; por lo tanto, en nuestro método ha sido necesario encontrar una nueva forma motivadora que despertara el interés del estudiante por la materia. El sistema se ha basado en hacer comprender al alumno el grado de utilidad que puede tener el Derecho Constitucional a través del trabajo de campo (Yániz, 2006).

- Crear hábitos de estudio diario. El gran contenido de información de la materia Derecho Constitucional 
llevaba a que el alumno se angustiara al final del curso; un volumen de trabajo que habitualmente cuesta asimilar si no se trabaja desde el comienzo con un método. Por lo tanto, ha habido que marcar unas pautas de estudio diario que disminuyeran dicha angustia y al mismo tiempo crearan hábitos de estudio.

- Comunicar en público. Estimular la participación oral en clase y, al mismo tiempo, hablar en público. Es evidente la dificultad y el temor escénico que sienten muchos alumnos al hablar en público; habilidad que, si se adquiere, puede ser de gran utilidad en su vida profesional. Por lo tanto, con este método es necesario que el alumno empiece desde el principio a ensayar hábitos de comunicación y exposición en público. La mejor manera de lograr esto es expresando su propio pensamiento o ideas, lo que le dará seguridad y confianza, toda vez que hay que buscar el modo en que el alumno exprese su propio pensamiento e ideas sobre la materia impartida.

- Trabajo en equipos interdisciplinares. Hacer patente la importancia del trabajo en equipo. En su vida profesional el alumno deberá llevar a cabo con éxito proyectos en equipo, independientemente del grado de amistad o simpatía que pueda tener con sus miembros. Desde el primer curso universitario el alumno debe ser consciente de su responsabilidad de trabajo como miembro de un equipo para conseguir un objetivo marcado por la empresa, por el profesor, etc., huyendo del trabajo en equipos formados por el grupo de amigos. Hay que dar importancia al trabajo en equipo en este sentido y valorar el grado de responsabilidad e implicación.

A la vez, en los grados de Periodismo, Comunicación Audiovisual y Relaciones Públicas y Publicidad, se han creado grupos interdisciplinares formados por estudiantes de las diferentes enseñanzas para potenciar y adaptar el trabajo a sus habilidades y especialidades.

- Razonamiento crítico. Enseñar a fundamentar opiniones. El colectivo de primer curso suele ser un alumnado joven, entre los 18 y los 25 años, una etapa de la vida en que la personalidad del individuo está formándose. El profesor, como formador, debe enseñar a pensar con rigor científico, con visión crítica, con un análisis neutral de los hechos. Hay que enseñar a utilizar los mecanismos de análisis científicos que den al alumno los criterios rigurosos para poder formar su propia opinión y personalidad. En definitiva, que «los alumnos construyan su propio conocimiento» (Bain, 2007, p. 28).

C) Competencias nucleares (objetivos de formación personal)

- Compromiso ético. Reforzar la importancia de los valores sociales y de los principios individuales de comportamiento para preservar y potenciar la democracia. Este es uno de los objetivos finales de la materia impartida. La democracia se basa en el ejercicio de la libertad responsable, y la responsabilidad para hacer uso de la libertad nos la dan los valores y los principios de comportamiento individuales. La importancia de los valores (responsabilidad, honradez, honestidad, tolerancia, fidelidad, etc.) son fundamentales para preservar una democracia sana. Hemos incidido constantemente con este objetivo a lo largo de los cursos académicos haciendo uso de abundantes ejemplos que pusieran en evidencia la falta de valores.

- Gestionar conocimientos. Comprender la realidad actual. Justamente esta materia es adecuada para que el alumno comprenda la realidad del momento. Muchos de los contenidos de la asignatura tienen un reflejo en el día a día que hay que aprovechar para estimular el interés del alumno por la materia y ayudar a su formación personal y profesional (Yániz, 2006).

- Participación directa de la sociedad en el aprendizaje. Esta es una de las competencias fundamentales: acercar a la sociedad el aprendizaje para que el estudiante conozca de primera mano nuestras instituciones $y$, a la vez, que las instituciones participen en el proceso de aprendizaje con una simbiosis mutua que enriquezca a ambas partes.

- Expresarse correctamente en público. Utilizar un lenguaje y una terminología adecuados a los conocimientos adquiridos.

\subsection{Planificación del trabajo}

Para conseguir estos objetivos se ha realizado el siguiente plan de trabajo, que ha sido pensado para que el engranaje encajara correctamente y quedaran la menor cantidad de aspectos posibles por atender. El plan de trabajo se ha basado en ocho ítems: 
- Clases magistrales de teoría.

- Clases prácticas.

- Un plan de trabajo y metodológico específico para los alumnos que no asistieran a clase.

- Apoyo de las tecnologías de la información y la comunicación (TIC).

- Planificación evaluativa equilibrada.

- Participación de la sociedad.

- Educación en valores.

- Uso de unas estrategias docentes en las que las habilidades del profesor fueran encaminadas a mostrarse cercano al alumno, captar su atención, ganarse su respeto y autoridad y convertirse en una referencia como persona y como fuente de conocimientos.

\subsubsection{Clases magistrales de teoría}

A) Desarrollo de cada clase (Imbernon, 2007)

- Introducción. Breve recordatorio de la clase anterior y situación contextual del nuevo tema, mencionando los puntos más importantes que se tratarán, con el objetivo de centrar el tema y crear interés.

- Desarrollo de la materia. En el transcurso de la clase se utilizan los siguientes recursos:

- Esquemas. Discurso expositivo a través de constantes esquemas en la pizarra y en proyección. La «visión esquemática», ordenada y clara de los conocimientos facilita en gran medida el aprendizaje.

- Ejemplificar los conocimientos que se pretenden transmitir. Introducir numerosos ejemplos de refuerzo, conocidos y de interés para el alumno, con la finalidad de que este comprenda los contenidos que se exponen. Ejemplificar es básico para transportar los conocimientos teóricos que se pretenden transmitir a una realidad conocida y cercana para el alumno.

- Uso de las nuevas TIC. Conexión permanente con las webs oficiales del Congreso, del Senado, del Parlament de Catalunya, del Poder Judicial, de la Organización de las Naciones Unidas (ONU), de la Unión Europea, etc. Utilizado en su justa medida, este recurso da credibilidad e ilustra los contenidos expuestos. También acerca la materia a un mundo tecnológico que el alumno suele manejar muy bien. El estudiante participa en la búsqueda de contenidos a través de sus dispositivos (iPhone, iPad, ordenadores, etc.), haciéndole cómplice de la investigación y evitando que sus dispositivos móviles estén ocupados en otras tareas no docentes.

- Página web. Desde el curso 2012-2013, y posteriores, se ha confeccionado expresamente para cada asignatura una página web que incluye numerosos vínculos e información de apoyo para el alumno, convirtiéndose en una herramienta muy valorada por el alumnado:

- Web del grado de Relaciones Laborales y Ocupación (<https://sites.google.com/site/constiacc/ relacions-laborals-i-ocupacio>).

- Web de los grados de Periodismo, Comunicación Audiovisual y Publicidad y Relaciones Públicas (<https://sites.google.com/site/constiaccperiodisme/>).

- Feedback con asiduidad. Para valorar el grado de asimilación de la materia impartida y avanzar progresivamente en el aprendizaje, es necesario que el profesor teste la comprensión de los contenidos explicados a los alumnos a través de preguntas, diálogos, aseveraciones interrogativas, etc. (feedback). En los PowersPoints se intercalan, aproximadamente cada 30 minutos, unas preguntas de opción múltiple o de definición y contenido corto para que la clase las responda. Esto crea cierto grado de competitividad entre los estudiantes, permite comprobar el grado de asimilación de la materia y rompe la monotonía de las explicaciones. También permite reforzar los contenidos poco asimilados. Últimamente se utilizan aplicaciones como Kahoot! y Nearpod.

- Resumen. Se sintetizan los principales conceptos impartidos. Antes de terminar la sesión hay que resumir muy sintéticamente los puntos expuestos más importantes. Esto permitirá reforzarlos y que el alumno los memorice, preparándole para la próxima sesión.

\section{B) Asimilación}

- Test quincenal. Cada dos semanas se preparará un test con 10 preguntas de elección múltiple sobre 
los contenidos impartidos en las clases anteriores, con el fin de obligar al alumno a repasar la materia dada y crear así en él hábitos de estudio diario. Estos test son evaluables.

\subsubsection{Clases prácticas}

Es en este bloque donde el alumno encuentra el sentido a los contenidos de las sesiones magistrales y donde se desarrollan muchas de las competencias planteadas como objetivos, dado que la participación del alumno será constante, así como la interrelación con la sociedad y con el profesor, lo que posibilitará la aplicación de las estrategias docentes planificadas. Se trabajan tres bloques:

\section{A) Refuerzo de la asimilación de los contenidos teóricos (clases magistrales)}

Para ello se profundizará en la preparación y en la exposición oral de temas impartidos en clase mediante trabajos en grupo. El objetivo es mejorar el aprendizaje de la materia impartida, iniciar al alumno en los hábitos de búsqueda, integrarlo en un equipo de trabajo y en la defensa oral y en público de un tema, y, lo más importante, encontrar la respuesta en la sociedad.

- Denominación de la práctica. «Reportaje/Trabajo de Investigación».

- Tipo de práctica. Reportaje/trabajo de investigación y exposición oral.

- Dinámica. Equipos de trabajo. La clase se divide en grupos de trabajo (3/4 alumnos). El número de grupos dependerá de los temas que haya para exponer y de los días de prácticas. Al principio del curso el profesor planificará un calendario de exposiciones orales y se formarán los equipos de trabajo, de tal manera que toda la clase se integre y participe en un grupo de trabajo que intervendrá cada semana, con independencia de los lazos afectivos que les unan, como sucede en los equipos de trabajo empresariales, con el fin de inculcar que el objetivo principal es conseguir el éxito de la misión encargada al equipo.

En los grados de Periodismo, Comunicación Audiovisual y Publicidad y Relaciones Públicas, los equipos han estado formados forzosamente por «estudiantes interdisciplinares» de cada enseñanza con la finalidad de que cada uno encontrara en el trabajo el espacio de sus habilidades formativas y pudiera desarrollar su aptitud adecuadamente (los estudiantes de Periodismo han realizado los guiones; los de Comunicación Audiovisual, la producción y posproducción de los materiales audiovisuales; los de Publicidad y Relaciones Públicas, anuncios, entrevistas y presentaciones). De esta manera cada estudiante encuentra en la materia un aspecto que le estimula y con el que puede practicar sus aptitudes y habilidades profesionales. En esta metodología, la materia de la asignatura se adapta a cada tipo de enseñanza, dado que, a menudo, el interés del estudiante de Periodismo por el Derecho Constitucional no es ni mucho menos el mismo que pueda tener el estudiante de Comunicación Audiovisual. Por lo tanto, hay que establecer una estrategia para que todos encuentren un estímulo y un interés en la materia.

- Materia. Los contenidos más importantes del programa de la asignatura.

\section{- Desarrollo:}

- Elaboración de un dosier monográfico. Para su creación se siguen criterios metodológicos de investigación, es decir, se plantea una metodología, se buscan fuentes bibliográficas, se añaden glosarios, anexos documentales/legislativos, se actualiza el tema con los personajes reales protagonistas de la materia (miembros del Gobierno, del Tribunal Constitucional, etc.). Desde el primer momento se pone un cuidado especial para que el alumno siga las normas de estilo propias de los trabajos de carácter científico. De este modo se empiezan a crear en el estudiante hábitos de buena redacción, inclusión de citas textuales, de referencias bibliográficas, de notas a pie de página, etc., con la finalidad de que los aplique en todos los trabajos que realizará durante sus estudios y en el trabajo de fin de grado (TFG).

- Elaboración de un vídeo de libre creación que sintetice el tema, con una duración de unos 15/20 minutos. Este recurso obligará a conocer y resumir el tema en profundidad, a fin de encontrar la información en la sociedad y exponerla de la manera más imaginativa posible, plasmado en imágenes. Esto conlleva, a menudo, que el alumno se ponga en contacto con instituciones y organismos y que conozca su realidad, ya que para efectuar el vídeo deberá visitar las instalaciones, hacer entrevistas 
a los responsables, recoger información y conocer de primera mano lo que se le ha explicado en clase. Esta actividad suele estimular al alumno y potencia la competitividad entre los equipos. Los miembros se reparten las tareas de presentador, entrevistador, guionista, etc., lo que los obliga a conocer el tema en profundidad y su realidad².

Por otra parte, el contacto con organismos, entidades e instituciones hace que el eco social de la universidad esté presente y sea muy valorado.

Estos vídeos son visualizados en clase por todos los alumnos durante cada semana del curso y cuentan con el valor añadido de que, en ellos, personas representativas de las principales instituciones del país (diputados, senadores, parlamentarios, magistrados, abogados, alcaldes, miembros de diferentes consejerías del Gobierno, miembros del Tribunal Constitucional, etc.) dan explicaciones a la clase sobre las preguntas que los alumnos les han formulado en relación a los temas impartidos.

Es un verdadero privilegio contar con personajes relevantes semanalmente en clase.

- Resumir el tema en un esquema de presentación (PowerPoint). El dosier elaborado se resumirá en un breve esquema de presentación.

- Exposición oral de cada uno de los miembros del grupo. Durante 15 minutos todos los miembros del equipo expondrán esquemáticamente y de manera individual el tema trabajado.

- Presentación y visionado del vídeo. El responsable del grupo presentará el vídeo en la clase y se visionará. En las clases de Periodismo, de Comunicación Audiovisual y de Publicidad y Relaciones Públicas, a demás del vídeo, se ha incorporado la realización de un spot (en formato vídeo) y de un póster publicitario (en formato papel, con unas dimensiones de $70 \times 110 \mathrm{~cm}$ ) para incentivar a los alumnos de Publicidad en la realización del trabajo.

\footnotetext{
2 Véanse las funciones del video en el aprendizaje: informativa (estructura la realidad), instructiva (desarrollo cognitivo), motivadora (atrae, interesa y motiva), evaluadora (autoobservación y análisis), investigadora (profundizar en el tema), metalinguística (lenguaje audiovisual), expresiva (grabación y edición), lúdica, innovadora, etc. En cuanto a las ventajas: versatilidad, motivación, cultura de la imagen, medio expresivo, mejor acceso a los significados, desarrollo de la imaginación y la intuición, etc. (<http://www.peremarques.net/videoori.htm> y <http://www.peremarques. net/temas $2 /$ t8.html>).
}

- Debate sobre el tema expuesto y visualización del vídeo con la participación de toda la clase. Una vez visionado y expuesto el tema, cada grupo de la clase efectúa una pregunta, abriendo un debate. Estas preguntas obligan al grupo que expone el tema a profundizar en los conocimientos para poder responder con soltura a las preguntas de la clase.

\section{B) Respuesta de las instituciones y de las per- sonalidades}

Después de cada entrevista, el profesor se dirige por carta a la institución o a la personalidad relevante para agradecerles su colaboración y el tiempo que han dedicado a los estudiantes. A menudo, la respuesta de las instituciones y de las personalidades es altamente positiva y alentadora, apoyando la iniciativa y estando predispuestos a colaborar en próximos cursos.

De esta manera se consigue vincular a las instituciones y a las personalidades al aprendizaje, aportando un conocimiento de primera mano a la clase, ya que los estudiantes conocen las instituciones de una manera directa y personal.

\section{C) Debates}

Hacer patente la importancia de la materia impartida en la realidad cotidiana que vive el alumno. A través de las noticias de los medios de comunicación que se producen cada día, se busca el trasfondo constitucional/estatutario/legal de cada noticia relevante, a fin de constatar la vigencia de la materia impartida en la realidad actual.

- Denominación de la práctica. «Debates Políticos» (El Día a Día de la Constitución/Estatuto, etc.).

- Tipo de práctica. Foros de discusión/liga de debates.

- Dinámica. La clase se divide en dos grupos de discusión paritarios, que defenderán posturas contradictorias.

- Materia. Debates sobre grandes temas recurrentes de la actualidad política, social, económica, etc., que aparecen en los medios de comunicación y que interesan al alumno (los políticos, la crisis, la inmigración, la religión, la monarquia/república, el independentismo, la sentencia del Estatuto de Cataluña, la corrupción, las nuevas leyes polémicas como el aborto, etc.) a fin de ver que la Constitución o el Es- 
tatuto son el trasfondo de muchas noticias diarias y que son temas coloquiales entre los propios alumnos, sus familiares y amigos, lo que motiva el aprendizaje para poder lograr una mayor y mejor opinión.

\section{- Desarrollo:}

- Calendario de debates. El profesor planifica y publica al inicio del curso un calendario de debates.

- Aportación de información. La semana previa al debate el alumno y el profesor aportan información a la clase a través de internet, de la web de la asignatura, etc., sobre:

- «Recortes de prensa/noticias». Relacionados con el tema de debate.

- «Legislación». Relacionada con el tema de debate (artículos de la Constitución, del Estatuto, de reglamentos del Parlamento, nuevas leyes, etc.), a fin de disponer de información legal y enriquecer el debate.

- Foro de discusión/liga de debate:

- «División de la clase en dos grupos: partidarios y detractores». Así se trabaja el razonamiento y la defensa de postulados contrarios a las propias opiniones personales, a la vez que se preserva el anonimato del pensamiento individual sobre temas a veces comprometidos.

- «Introducción del profesor al debate». El profesor hace una introducción de la temática del debate y estimula a los alumnos para que formulen preguntas.

- «Rebatir al compañero». Los alumnos deben rebatir razonadamente las posturas contrarias surgidas en el debate.

- «Ir a la fuente de la noticia». Cuando el debate lo requiera se irá a la fuente de la noticia, al origen del tema debatido. En esta parte se trabaja cómo fundamentar una opinión a través de la búsqueda de las fuentes con el empleo constante de las TIC (búsqueda por internet de leyes, leyes de presupuestos, reglamentos de las Cámaras de los Parlamentos, webs institucionales, etc.), aprendiendo a cribar la información y a analizar los argumentos a favor y en contra.

- "Conclusiones». El profesor induce a la clase para que saque conclusiones del tema debatido.
- Trabajo fin de curso. Elaboración de un resumen de cada sesión debatida o realización de un test evaluable de contenidos de los debates.

\subsubsection{Plan de trabajo para los alumnos que no asisten a clase}

Para los alumnos que, por motivos plenamente justificados, no pueden asistir a clase, se prepara el siguiente plan de trabajo:

- Tres cuadernos de evaluación a distancia. Test de preguntas de elección múltiple y de desarrollo sobre el contenido de la materia del programa, algunas a contestar en un vídeo (como un examen oral). Este recurso del vídeo es útil porque obliga al alumno a aprenderse la respuesta y a exponerla oralmente ante la cámara, lo que evita "copiar y pegar». Los cuadernos se envían mensualmente al profesor por vía electrónica, quien se los devolverá a los alumnos ya evaluados.

- Reseña bibliográfica. El alumno puede elegir entre tres publicaciones seleccionadas por el profesor.

- Trabajo monográfico. Sobre temas de actualidad política.

- Examen. Teórico y práctico.

- Tutoría online con el profesor. A través del correo electrónico.

- Página web de la asignatura. Donde el alumno podrá encontrar toda la materia del curso y multitud de links.

\subsubsection{Apoyo de las $T I C$}

Como hemos dicho, la utilización de las TIC es constante en el curso, de tal manera que se ha creado una página web específica para cada asignatura y grado, donde el estudiante puede complementar la investigación con numerosos links y materiales que hay colgados y que se actualizan constantemente según los acontecimientos políticos y sociales. Estas webs se han elaborado personalmente para apoyar al estudiante (web del Grado de Relaciones Laborales y Ocupación [<https://sites.google. $\mathrm{com} /$ site/constiacc/relacions-laborals-i-ocupacio>] y web de los grados de Periodismo, Comunicación Audiovisual y Publicidad y Relaciones Públicas [<https://sites.google. com/site/constiaccperiodisme/>]). 


\subsubsection{Evaluaciones}

Esta evaluación continuada se viene aplicando desde mucho antes de la implantación del Plan Bolonia, siendo en esos momentos un sistema innovador en la materia.

Se evalúa en un $50 \%$ la teoría y en un $50 \%$ la práctica (véase tabla 3). La evaluación de la teoría se realiza a través de los test quincenales y de un examen final de desarrollo, en el que el grado de asimilación de contenidos y los hábitos de estudio alcanzados a través de los test son los parámetros evaluables. La evaluación de la práctica se realiza a través del cómputo de evaluaciones sobre los dos bloques de la práctica. En la exposición oral del trabajo de investigación «Reportaje/Trabajo de Investigación» se valora la comunicación oral, la información aportada, la elaboración del vídeo, la investigación empleada en el dosier de trabajo que se va a presentar, las pautas de estilo, la metodología y el grado de consecución de los objetivos como equipo de trabajo.

En cuanto a los foros de discusión «Debates Políticos» se valora el razonamiento crítico procedente de un análisis aséptico, el compromiso ético de los valores sociales y de los principios individuales de comportamiento, la comprensión de la realidad político-social actual y la aplicación de los contenidos a la realidad, identificando el trasfondo constitucional o legal de los acontecimientos del día a día (Villardón, 2006). Un test final sirve para evaluar los hábitos de estudio y la asimilación de los contenidos de las diferentes materias de los debates. Se tiene en cuenta la intervención en los debates. Al final, se pide al propio alumno que haga una autoevaluación de los conocimientos adquiridos que sirve para constatar que la nota parametrizada se ajusta, en la mayoría de los casos, a la que el alumno espera.

\subsubsection{Participación de la sociedad}

La elaboración del reportaje de investigación sirve para conectar la universidad con la sociedad y sus instituciones. Los estudiantes deben buscar la información en la propia sociedad, preguntando en las instituciones, en las Administraciones, entrevistando a personajes relevantes, etc. De este modo, el estudiante conocerá de primera mano nuestras instituciones, lo que enriquecerá notablemente su aprendizaje y dará a conocer el trabajo docente de la universidad a la sociedad. La implicación de la sociedad es muy remarcable (véase posteriormente el apartado de los resultados).

Parte de este conocimiento se ha adaptado para ser transferido en las Aulas de Extensión Universitaria de Gente Mayor o de la Tercera Edad (con sesiones en varias localidades).

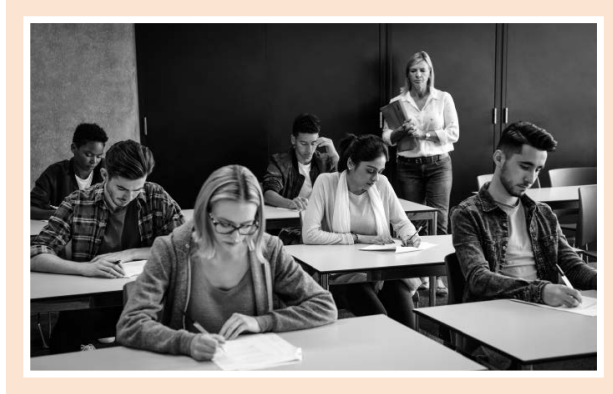

Tabla 3. Actividades evaluativas y su peso sobre la nota

\begin{tabular}{|c|c|}
\hline Actividades evaluativas & $\%$ peso/nota \\
\hline $\begin{array}{l}\text { Pruebas de desarrollo (preguntas abiertas } \\
\text { sobre un tema) }\end{array}$ & $25 \%$ \\
\hline Pruebas objetivas de preguntas cortas ....... & \\
\hline Pruebas objetivas tipo test ............................ & $25 \%$ \\
\hline \multicolumn{2}{|l|}{ Pruebas prácticas: } \\
\hline 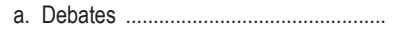 & $20 \%$ \\
\hline b. Presentaciones/exposiciones ................. & \\
\hline $\begin{array}{l}\text { c. Resolución de problemas, ejercicios en } \\
\text { el aula }\end{array}$ & \multirow{7}{*}{$30 \%$} \\
\hline d. Prácticas a través de las TIC ................. & \\
\hline e. Prácticas externas ..... & \\
\hline 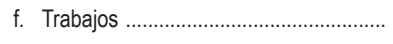 & \\
\hline g. Foros de discusión ................................. & \\
\hline h. Resolución de problemas ........................ & \\
\hline i. Aprendizaje basado en problemas (PBL) & \\
\hline Pruebas orales & \\
\hline 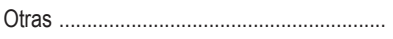 & \\
\hline
\end{tabular}

Fuente: Guía Docente curso 2017-2018 


\section{Los estudiantes deben buscar la información en la propia sociedad, preguntando en las instituciones, en las Administraciones, entrevistando a personajes relevantes}

\subsubsection{Educar en valores}

El interés por los debates sobre temas de actualidad hace que se den a menudo condiciones para remarcar la importancia de los valores y de los principios de comportamiento social (responsabilidad, tolerancia, comprensión, honradez, etc.) como bases fundamentales de nuestra sociedad. Es esta educación en valores a la que se le da relevancia en todos los comportamientos del curso (responsabilidad en la formación de equipos de trabajo; se trabaja en clase la confianza, la honradez, etc.). También, a través de los debates se buscan situaciones y ejemplos que hagan patente la necesidad de mantener y preservar los valores. El ejemplo recurrente son los debates sobre la corrupción, los políticos, etc. Si conseguimos este compromiso con los valores, habremos contribuido a formar a profesionales y a ciudadanos, a la vez que conseguiremos una sociedad más justa.

\subsubsection{Estrategias docentes}

Para conseguir las competencias y que la metodología expuesta dé el máximo rendimiento, es necesario que el profesor aplique una serie de estrategias o habilidades personales:

\section{A) Actitud personal del docente}

- Estar motivado. El profesor debe estar convencido de que lo que hace es lo que le gusta (dar lo mejor de uno mismo).

- Ilusión y pasión en la transmisión de los conocimientos. Estos sentimientos se contagian y son de capital importancia para estimular el interés por la materia.

- Convencimiento. Mostrarse creíble, veraz y con experiencia, y estar al día en los conocimientos.
- Neutralidad en las explicaciones. Razones argumentadas a favor y en contra.

- Mantener unos principios de comportamiento y unos valores.

- Obrar con equidad.

- Razonar y justificar las decisiones.

- Objetivos:

- Ganar el respeto y la autoridad y al mismo tiempo ser cercano con el alumno.

- Ser una referencia como persona y como fuente de conocimientos para el alumno.

B) Actividades de aprendizaje

- Esquematización de la transmisión de la información. Publicar con asiduidad en Moodle y en la web de la asignatura esquemas de las materias importantes.

- Resaltar lo que es importante.

- Crear la necesidad de aprender. Explicar la vertiente de los contenidos más útiles para el alumno.

- Intentar capturar y seducir a la clase con los contenidos. Para ello se recurrirá al tono y al ritmo de la palabra y a los ejemplos.

- Objetivo. Captar la atención permanente del alumno.

C) Sintonizar con los alumnos y con las instituciones

- Interactuar con la clase. Comunicación previa personal y verbal intrascendente con el alumno/grupo antes de iniciar las clases. El objetivo es acercar distancias.

El interés por los debates sobre temas de actualidad hace que se den a menudo condiciones para remarcar la importancia de los valores y de los principios de comportamiento social (responsabilidad, tolerancia, comprensión, honradez, etc.) como bases fundamentales de nuestra sociedad 
- Interés por las cosas superfluas del alumno. El objetivo es interesarse por el alumnado.

- Explicar para cada alumno y para todos a la vez a través de la mirada. Que cada uno sienta que la explicación va dirigida a él. El objetivo es personalizar la exposición.

- Buscar la participación desde el principio. Los objetivos anteriores facilitarán la participación del alumno.

- Detectar a los alumnos más marginados e iniciar acciones de integración (extranjeros, personas mayores, líderes díscolos, etc.). El objetivo es que todo el colectivo se sienta integrado en la clase y se minimice la marginación.

- Predisposición y disposición para solucionar rápidamente problemas y dudas de los alumnos. Esto se hará a través de tutorías personales u online. El objetivo es que el alumno note que el profesor está a su lado si lo necesita.

- Objetivos. Todos estos estímulos estarán encaminados a que el profesor se muestre cercano y colaborador con el alumno.

- Mostrar gratitud y crear vínculos con las instituciones colaboradoras. A menudo el feedback es altamente positivo y motivador. Se ha detectado un interés por parte de la sociedad en interactuar con la URV.

\section{RESULTADOS OBTENIDOS}

\subsection{Parametrización de datos}

Para constatar el grado de eficacia del método docente empleado, se ha llevado a cabo una estadística por curso impartido en la que desde 2009 se han registrado diariamente, en una hoja de cálculo Excel, una serie de parámetros, entre los que destacamos: porcentaje de asistencia a clase a través de la firma de cada alumno (véanse tabla 4 y figura 1), evaluación de los test, intervenciones en las exposiciones orales, vídeo y participación en los foros de discusión, etc. (véase tabla 5). Todos estos parámetros nos han per- mitido seguir la trayectoria individualizada de cada estudiante (véase figura 2), incluso en clases muy numerosas (200 estudiantes semanales), con gráficos automatizados día a día que reflejan el seguimiento de las sesiones, la participación y la evolución individual. Además, la parametrización nos ha permitido disponer de una base de datos de 10 años muy completa con la trayectoria de cada estudiante.

También, al final de curso, se han realizado unas encuestas anónimas con el nombre «Ayúdame a Mejorar», destinadas a detectar la valoración que ha hecho el alumnado del método utilizado y del plan de trabajo llevado a cabo, con el fin de mejorar para el curso próximo las carencias que hayan podido producirse durante ese año académico. Por último, están las encuestas de opinión de los alumnos sobre la actividad docente del profesorado, que cada año hace la propia universidad de forma institucional.

Con estos elementos se han podido parametrizar los resultados obtenidos, lo que nos ha permitido constatar la bondad del método docente expuesto y el grado de interés que despiertan en el alumnado los contenidos de la asignatura.

La asistencia a las clases es parametrizada a través de un gráfico que permite ver y analizar las causas de los resultados (porcentajes) más bajos (véanse tabla 4 y figura 1). Con los datos parametrizados se elabora automáticamente un gráfico individual de la evolución de cada estudiante en comparación a la media de la clase para analizar y corregir su evolución a través de tutorías personalizadas (véase figura 2).

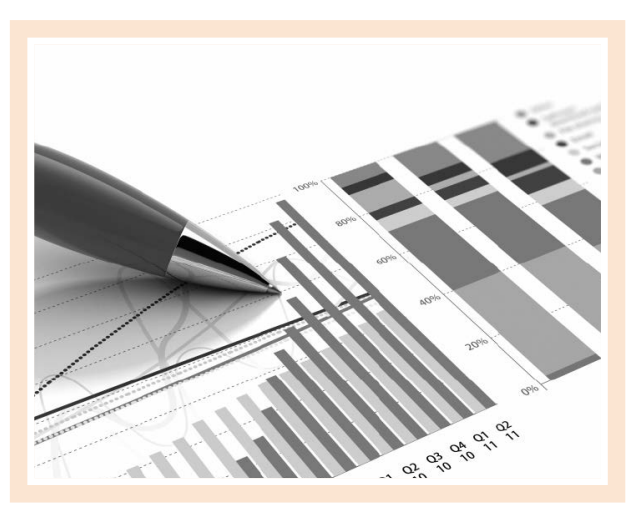




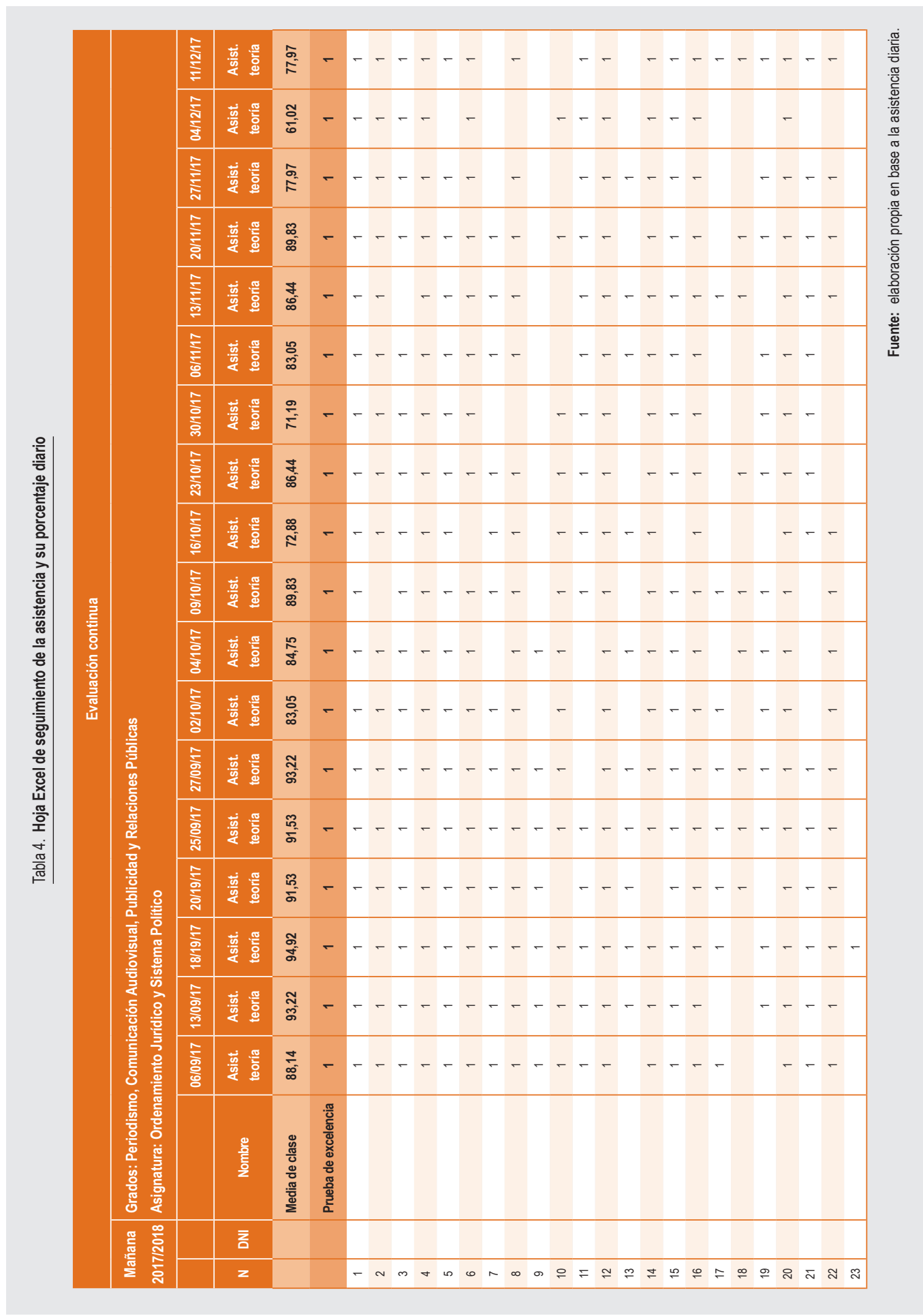




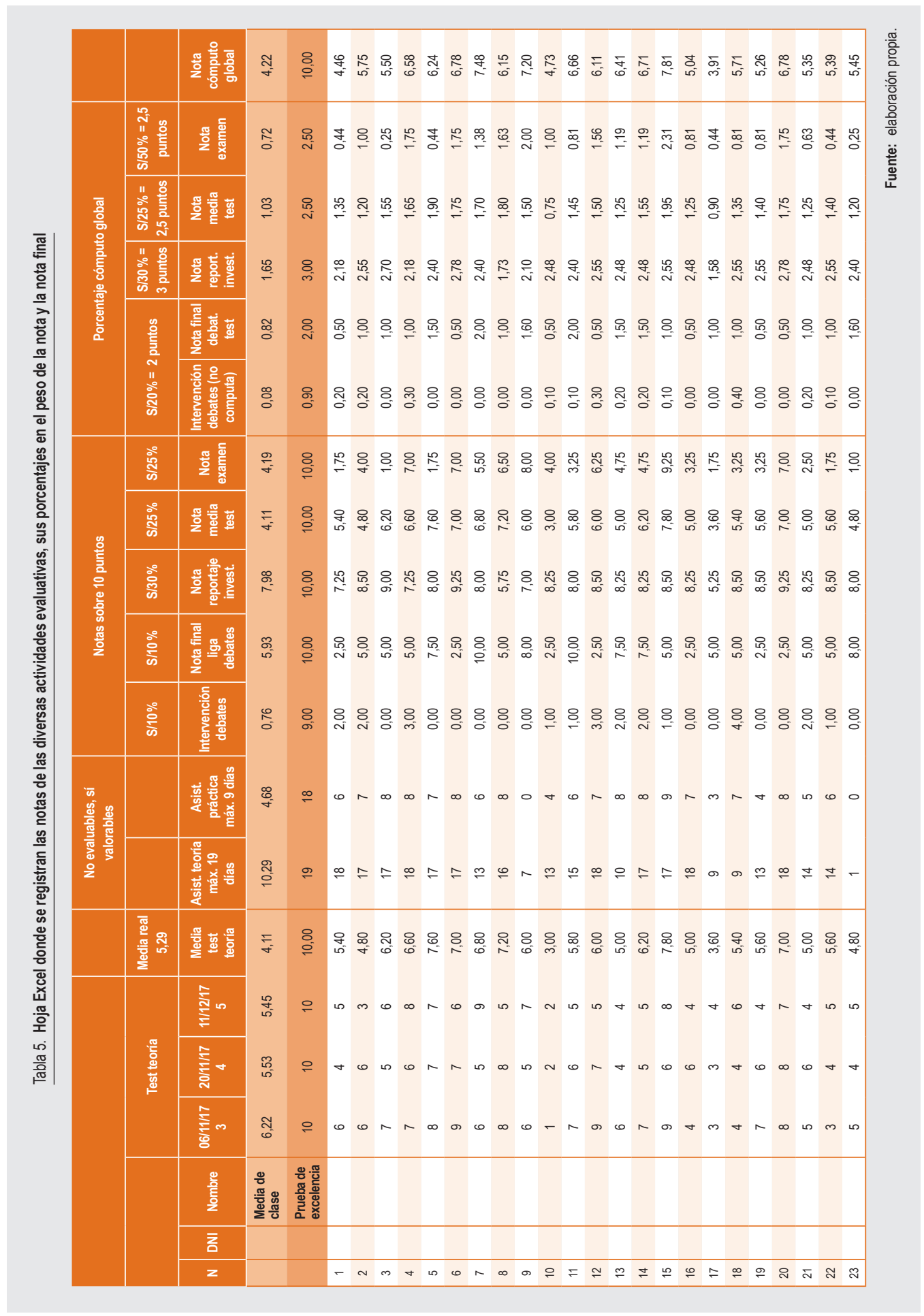




\section{Figura 1. Gráfico evolutivo de asistencia diaria}

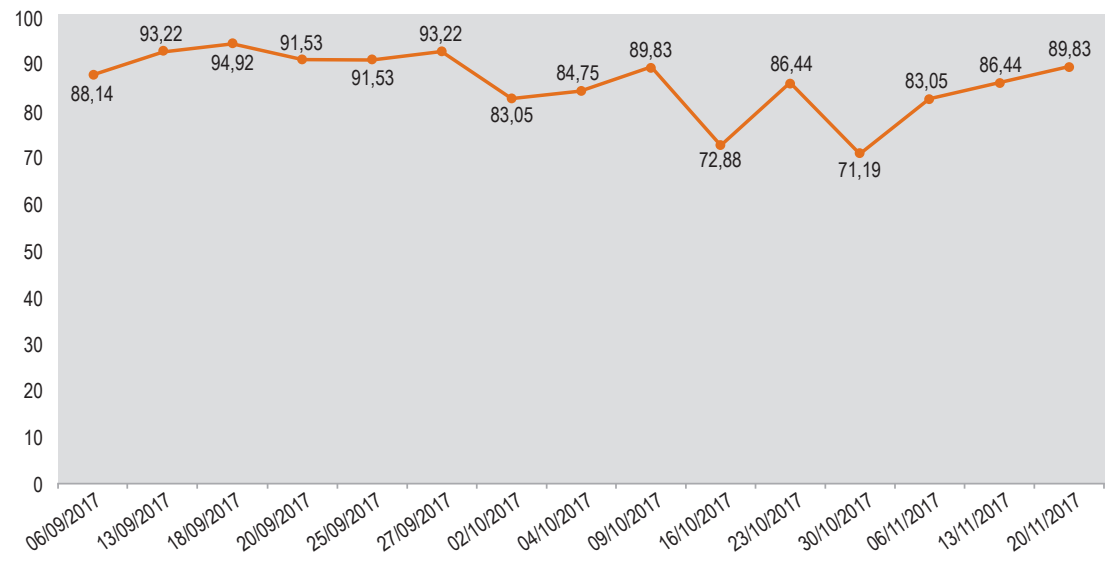

Fuente: elaboración propia en función del registro diario de asistencia a clase.

Figura 2. Gráfico individual de la evolución de cada alumno en comparación con la media de la clase (desglosado por tipo de actividades)

Evaluación continua

\section{Nombre del alumno:}

Ficha individual de cada alumno

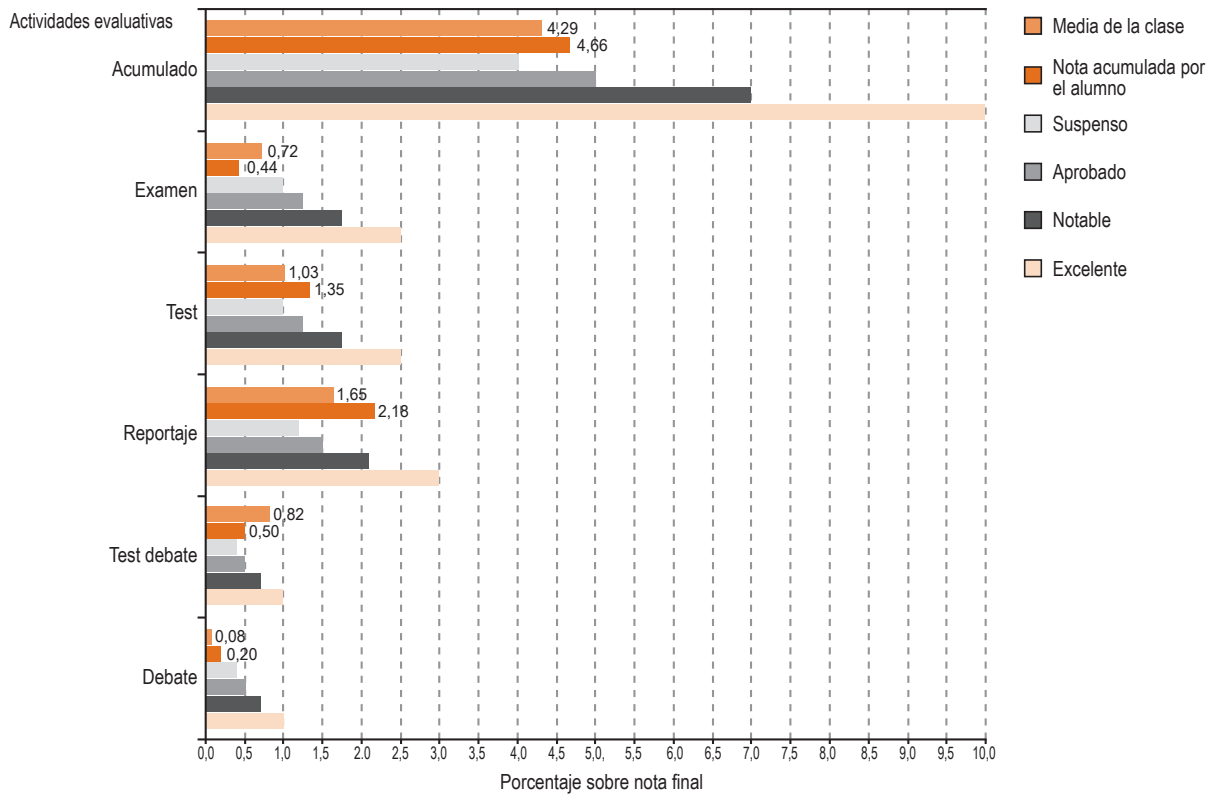

Fuente: elaboración propia en función del cómputo global de notas individuales de cada alumno en comparación con la media de la clase. 


\subsection{Grado de asistencia a clase e intervención en los debates}

Como se puede constatar en las tablas 6 y 7 , los resultados sitúan la asistencia a clase de los alumnos en una media de un $80,63 \%$ (un 75,37\%, en el caso de la Facultad de Ciencias Jurídicas, y un 85,90\%, en el caso de la Facultad de Letras) y sus intervenciones en los debates en un $38,32 \%$ (un 40,65\%, en el caso de la Facultad de Ciencias Jurídicas, y un $36 \%$, en el caso de la Facultad de Letras).

Tabla 6. Porcentaje de asistencia y participación en la Facultad de Ciencias Jurídicas (grado de Relaciones Laborales y Ocupación)

\begin{tabular}{|c|c|c|c|c|}
\hline Grado & Curso & Grupo & Asistencia a clase & Intervención debates \\
\hline Relaciones Laborales y Ocupación ............. & $2009-2010$ & Tarde & & $65,48 \%$ \\
\hline Relaciones Laborales y Ocupación ............ & $2010-2011$ & $\begin{array}{c}\text { Mañana } \\
\text { Tarde }\end{array}$ & $\begin{array}{l}75,89 \% \\
70,79 \%\end{array}$ & $\begin{array}{l}40,50 \% \\
32,01 \%\end{array}$ \\
\hline Relaciones Laborales y Ocupación ............. & $2011-2012$ & $\begin{array}{c}\text { Mañana } \\
\text { Tarde }\end{array}$ & $75,37 \%$ & $\begin{array}{l}44,28 \% \\
22,00 \%\end{array}$ \\
\hline Relaciones Laborales y Ocupación ............. & $2012-2013$ & $\begin{array}{c}\text { Mañana } \\
\text { Tarde }\end{array}$ & $\begin{array}{l}73,20 \% \\
70,89 \%\end{array}$ & $\begin{array}{l}25,10 \% \\
33,00 \%\end{array}$ \\
\hline Relaciones Laborales y Ocupación ............. & 2013-2014 & $\begin{array}{c}\text { Mañana } \\
\text { Tarde }\end{array}$ & $\begin{array}{l}76,65 \% \\
64,00 \%\end{array}$ & $\begin{array}{l}48,60 \% \\
40,65 \%\end{array}$ \\
\hline Relaciones Laborales y Ocupación ............. & 2014-2015 & Mañana & $71,70 \%$ & $70,63 \%$ \\
\hline Relaciones Laborales y Ocupación ............. & $2015-2016$ & Mañana & $76,60 \%$ & $47,38 \%$ \\
\hline Relaciones Laborales y Ocupación ............. & 2016-2017 & Mañana & $76,92 \%$ & $38,46 \%$ \\
\hline Relaciones Laborales y Ocupación ............. & $2017-2018$ & Mañana & $68,46 \%$ & $59,86 \%$ \\
\hline Media & & & $75,37 \%$ & $40,65 \%$ \\
\hline
\end{tabular}

Fuente: elaboración propia (registro de firmas y participación).

Tabla 7. Porcentaje de asistencia y participación en la Facultad de Letras (grados de Periodismo, Comunicación Audiovisual y Publicidad y Relaciones Públicas)

\begin{tabular}{|l|c|c|c|c|}
\multicolumn{1}{|c|}{ Grado } & Curso & Grupo & Asistencia a clase & Intervención debates \\
\hline $\begin{array}{l}\text { Periodismo, Comunicación Audiovisual y } \\
\text { Publicidad y Relaciones Públicas ............ }\end{array}$ & $2009-2010$ & Tarde & $85,90 \%$ & $40,40 \%$ \\
Periodismo, Comunicación Audiovisual y & $2015-2016$ & Mañana & $88,06 \%$ & $27,12 \%$ \\
Publicidad y Relaciones Públicas ............ & & Tarde & $83,30 \%$ & $36,00 \%$ \\
\end{tabular}


Tabla 7. Porcentaje de asistencia y participación en la Facultad de Letras (grados de Periodismo, Comunicación Audiovisual y Publicidad y Relaciones Públicas) (cont.)

\begin{tabular}{|l|c|c|c|c|}
\multicolumn{1}{|c|}{ Grado } & Curso & Grupo & Asistencia a clase & Intervención debates \\
\hline ....... & & Mañana & $91,14 \%$ & $27,54 \%$ \\
Periodismo, Comunicación Audiovisual y & $2016-2017$ & Tarde & $80,43 \%$ & $45,83 \%$ \\
Publicidad y Relaciones Públicas ............. & & Mañana & $87,29 \%$ & $21,79 \%$ \\
\hline Periodismo, Comunicación Audiovisual y & $2017-2018$ & Tarde & $80,82 \%$ & $12,84 \%$ \\
\hline Publicidad y Relaciones Públicas ............. & & & $85,90 \%$ & $36,00 \%$ \\
\hline Media ................................................ & & & \\
\hline
\end{tabular}

Fuente: elaboración propia (registro de firmas y participación).

\subsection{Valoración del plan de trabajo por los propios alumnos}

Los alumnos participantes (un total de 1.021 encuestados) le confieren a esta metodología una nota de un 8,5 sobre 10. Como se puede observar en la tabla 8 , destaca la valoración de las clases magistrales, de los test y de la web.

\begin{tabular}{|c|c|c|c|c|c|c|c|c|}
\hline \multirow[b]{2}{*}{ Facultad } & \multirow[b]{2}{*}{ Grado } & \multirow[b]{2}{*}{ Curso } & \multirow[b]{2}{*}{$\begin{array}{l}\text { Número de } \\
\text { encuestas }\end{array}$} & \multirow[b]{2}{*}{$\begin{array}{c}\text { Clase } \\
\text { magistral }\end{array}$} & \multicolumn{2}{|c|}{ Pruebas prácticas } & \multirow{2}{*}{$\begin{array}{c}\text { Pruebas } \\
\text { objetivas } \\
\text { Test }\end{array}$} & \multirow{2}{*}{$\begin{array}{c}\text { Soporte } \\
\text { Web } \\
\text { asignatura }\end{array}$} \\
\hline & & & & & \begin{tabular}{|c} 
Exposiciones \\
orales
\end{tabular} & Debates & & \\
\hline \multirow{10}{*}{$\begin{array}{l}\text { Ciencias } \\
\text { Jurídicas }\end{array}$} & RelacionesLaboralesyOcupación & 2008-2009 & 15 & & 7,40 & 8,40 & & \\
\hline & RelacionesLaboralesyOcupación & $2009-2010$ & 15 & & 9,00 & 8,70 & & \\
\hline & RelacionesLaboralesy Ocupación & $2010-2011$ & 75 & & 7,80 & 7,90 & & \\
\hline & RelacionesLaboralesyOcupación & 2011-2012 & 80 & 9,00 & 7,90 & 7,80 & 8,00 & \\
\hline & RelacionesLaboralesyOcupación & $2012-2013$ & 90 & 9,00 & 7,60 & 8,20 & 8,10 & 9,70 \\
\hline & RelacionesLaboralesyOcupación & 2013-2014 & 69 & 9,00 & 8,30 & 8,10 & 8,40 & 9,50 \\
\hline & RelacionesLaboralesyOcupación & $2014-2015$ & 50 & 8,70 & 8,20 & 8,10 & 8,20 & 9,30 \\
\hline & RelacionesLaboralesyOcupación & $2015-2016$ & 47 & 9,30 & 7,10 & 8,50 & 9,00 & 8,40 \\
\hline & RelacionesLaboralesyOcupación & 2016-2017 & 62 & 8,10 & 8,00 & 8,00 & 7,90 & 8,20 \\
\hline & RelacionesLaboralesyOcupación & $2017-2018$ & 57 & 8,70 & 8,20 & 8,20 & 7,90 & 8,30 \\
\hline Subtotal & & & 560 & 8,80 & 7,90 & 8,20 & 9,40 & 8,90 \\
\hline
\end{tabular}


Tabla 8. Valoración del plan de trabajo por los estudiantes (encuesta «Ayúdame a Mejorar») (cont.)

\begin{tabular}{|c|c|c|c|c|c|c|c|c|}
\hline & & & & & \multicolumn{2}{|c|}{ Pruebas prácticas } & \multirow{2}{*}{$\begin{array}{c}\begin{array}{c}\text { Pruebas } \\
\text { objetivas }\end{array} \\
\text { Test }\end{array}$} & \multirow{2}{*}{$\begin{array}{c}\text { Soporte } \\
\text { Web } \\
\text { asignatura }\end{array}$} \\
\hline Facultad & Grado & Curso & $\begin{array}{l}\text { Número de } \\
\text { encuestas }\end{array}$ & $\begin{array}{c}\text { Clase } \\
\text { magistral }\end{array}$ & $\begin{array}{c}\text { Exposiciones } \\
\text { orales }\end{array}$ & Debates & & \\
\hline \multicolumn{9}{|l|}{$\ldots / \ldots$} \\
\hline \multirow{4}{*}{ Letras } & $\begin{array}{l}\text { Periodismo, Comunicación Au- } \\
\text { diovisual y Publicidad y Relacio- } \\
\text { nes Públicas }\end{array}$ & $2014-2015$ & 112 & 7,60 & 8,00 & 7,00 & 8,80 & 8,50 \\
\hline & $\begin{array}{l}\text { Periodismo, Comunicación Au- } \\
\text { diovisual y Publicidad y Relacio- } \\
\text { nes Públicas ............................... }\end{array}$ & 2015-2016 & 115 & 8,60 & 8,10 & 8,00 & 8,70 & 8,50 \\
\hline & 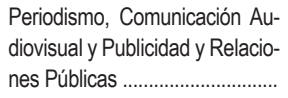 & 2016-2017 & 113 & 8,60 & 8,40 & 8,50 & 8,30 & 8,20 \\
\hline & $\begin{array}{l}\text { Periodismo, Comunicación Au- } \\
\text { diovisual y Publicidad y Relacio- } \\
\text { nes Públicas }\end{array}$ & $2017-2018$ & 121 & 8,40 & 8,30 & 8,20 & 7,90 & 8,60 \\
\hline Subtotal & & & 461 & 8,30 & 8,20 & 7,93 & 8,43 & 8,45 \\
\hline Media & & & 1.021 & 8,60 & 8,10 & 8,10 & 8,90 & 8,70 \\
\hline
\end{tabular}

Fuente: elaboración propia basada en las encuestas a los estudiantes.

\subsection{Resultados de las evaluaciones finales}

Respecto a los grados de Periodismo, Comunicación Audiovisual, Publicidad y Relaciones Públicas, la media de aprobados en la primera convocatoria está en un $59,26 \%$; la media de notables, en un $29,17 \%$; la media de suspensos, en un $5,72 \%$; y la media de no presentados, en un 3,45\% (véase tabla 9). Esto nos da una tasa de éxito del $93,31 \%$ y una tasa de rendimiento del $86,62 \%$ (véase tabla 10 ).

Tabla 9. Calificación de actas en los grados de Periodismo, Comunicación Audiovisual y Publicidad y Relaciones Públicas

\begin{tabular}{|l|c|c|c|c|c|c|c|}
\multicolumn{1}{|c|}{ Grado } & $\begin{array}{c}\text { Cursol } \\
\text { Mañana/Tarde }\end{array}$ & $\begin{array}{c}\text { No } \\
\text { presentados }\end{array}$ & Suspensos & Aprobados & Notables & Excelentes & MH \\
\hline Periodismo ................................ & $2009-2010$ & $21,21 \%$ & $0,00 \%$ & $45,45 \%$ & $30,30 \%$ & $3,03 \%$ & $3,03 \%$ \\
Comunicación Audiovisual .............. & $2009-2010$ & $34,29 \%$ & $11,43 \%$ & $40,00 \%$ & $8,57 \%$ & $5,71 \%$ & \\
Publicidad y Relaciones Públicas ... & $2009-2010$ & $15,62 \%$ & & $68,75 \%$ & $15,62 \%$ & \\
Periodismo ................................ & Mañana & $3,45 \%$ & $3,45 \%$ & $57,72 \%$ & $41,38 \%$ & \\
$2014-2015$ & Tarde & $0,00 \%$ & $7,14 \%$ & $42,86 \%$ & $50,00 \%$ & \\
& & & & & &
\end{tabular}


Tabla 9. Calificación de actas en los grados de Periodismo, Comunicación Audiovisual y Publicidad y Relaciones Públicas (cont.)

\begin{tabular}{|c|c|c|c|c|c|c|c|}
\hline Grado & $\begin{array}{c}\text { Cursol } \\
\text { Mañana/Tarde }\end{array}$ & $\begin{array}{c}\text { No } \\
\text { presentados }\end{array}$ & Suspensos & Aprobados & Notables & Excelentes & MH \\
\hline \multicolumn{8}{|l|}{$\ldots / \ldots$} \\
\hline Comunicación Audiovisual ................. & Mañana & $0,00 \%$ & $7,41 \%$ & $59,26 \%$ & $33,33 \%$ & & \\
\hline $2014-2015$ & Tarde & $8,70 \%$ & $0,00 \%$ & $73,91 \%$ & $17,39 \%$ & & \\
\hline Publicidad y Relaciones Públicas ... & Mañana & $0,00 \%$ & $7,69 \%$ & $38,46 \%$ & $53,85 \%$ & & \\
\hline $2014-2015$ & Tarde & $16,67 \%$ & $4,17 \%$ & $50,00 \%$ & $29,17 \%$ & & \\
\hline 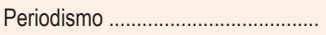 & Mañana & $11,54 \%$ & $0,00 \%$ & $65,38 \%$ & $23,08 \%$ & & \\
\hline 2015-2016 & Tarde & $0,00 \%$ & $6,66 \%$ & $33,33 \%$ & $60,00 \%$ & & \\
\hline Comunicación Audiovisual ............... & Mañana & $0,00 \%$ & $0,00 \%$ & $66,66 \%$ & $33,33 \%$ & & \\
\hline $2015-2016$ & Tarde & $3,85 \%$ & $0,00 \%$ & $76,92 \%$ & $19,23 \%$ & & \\
\hline Publicidad y Relaciones Públicas ... & Mañana & $0,00 \%$ & $0,00 \%$ & $70,83 \%$ & $29,16 \%$ & & \\
\hline $2015-2016$ & Tarde & $0,00 \%$ & $0,00 \%$ & $52,94 \%$ & $47,05 \%$ & & \\
\hline 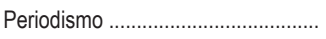 & Mañana & $0,00 \%$ & $0,00 \%$ & $54,16 \%$ & $45,83 \%$ & & \\
\hline 2016-2017 & Tarde & $7,14 \%$ & $7,14 \%$ & $64,28 \%$ & $21,42 \%$ & & \\
\hline Comunicación Audiovisual ................ & Mañana & $7,69 \%$ & $0,00 \%$ & $65,38 \%$ & $26,92 \%$ & & \\
\hline 2016-2017 & Tarde & $0,00 \%$ & $18,75 \%$ & $56,25 \%$ & $25,00 \%$ & & \\
\hline Publicidad y Relaciones Públicas ... & Mañana & $0,00 \%$ & $0,00 \%$ & $69,23 \%$ & $30,76 \%$ & & \\
\hline 2016-2017 & Tarde & $14,28 \%$ & $14,28 \%$ & $64,28 \%$ & $7,14 \%$ & & \\
\hline Periodismo & Mañana & $0,00 \%$ & $5,00 \%$ & $15,00 \%$ & $80,00 \%$ & & \\
\hline $2017-2018$ & Tarde & $4,54 \%$ & $0,00 \%$ & $40,90 \%$ & $45,45 \%$ & $4,54 \%$ & \\
\hline Comunicación Audiovisual ................ & Mañana & $0,00 \%$ & $0,00 \%$ & $57,14 \%$ & $42,85 \%$ & & \\
\hline $2017-2018$ & Tarde & $3,33 \%$ & $0,00 \%$ & $53,33 \%$ & $36,66 \%$ & $6,66 \%$ & \\
\hline Publicidad y Relaciones Públicas ... & Mañana & $4,00 \%$ & $4,00 \%$ & $48,00 \%$ & $40,00 \%$ & $4,00 \%$ & \\
\hline $2017-2018$ & Tarde & $5,55 \%$ & $0,00 \%$ & $44,44 \%$ & $50,00 \%$ & & \\
\hline Media & & $3,45 \%$ & $5,72 \%$ & $59,26 \%$ & $29,17 \%$ & $4,37 \%$ & $3,03 \%$ \\
\hline
\end{tabular}

Nota. $\mathrm{MH}=$ matricula de honor.

Fuente: elaboración propia (estadística sacada de las actas firmadas en la primera convocatoria). 
Tabla 10. Tasas de éxito y de rendimiento en los grados de Periodismo, Comunicación Audiovisual y Publicidad y Relaciones Públicas

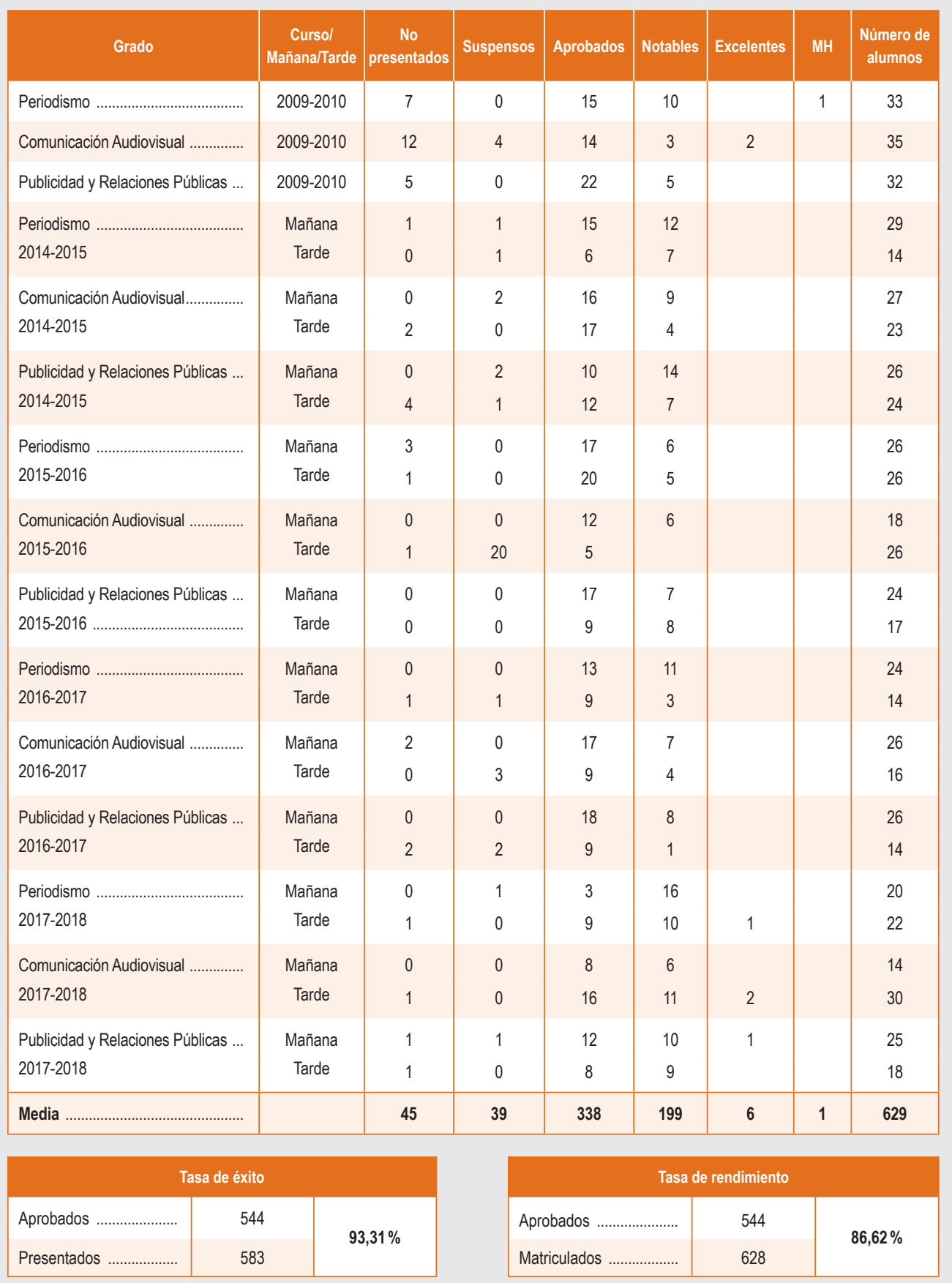

Fuente: elaboración propia (estadística sacada de las actas firmadas en la primera convocatoria). 
En cuanto al grado de Relaciones Laborales y Ocupación, la media de alumnos aprobados en la primera convocatoria se sitúa en torno al $50 \%$; la media de notables es de un $21,15 \%$; la media de los suspensos alcanza el $16,39 \%$; y la media de los no presentados, el $16,18 \%$ (véase tabla 11). La tasa de éxito se sitúa en torno al $78,86 \%$ y la tasa de rendimiento en un $66,52 \%$ (véase tabla 12 ).

\begin{tabular}{|c|c|c|c|c|c|c|c|}
\hline \multirow[b]{2}{*}{ Grado } & \multicolumn{5}{|c|}{ Calificación de actas en el grado de Relaciones Laborales y Ocupación } & \multirow[b]{2}{*}{ Excelentes } & \multirow[b]{2}{*}{ MH } \\
\hline & Curso & No presentados & Suspensos & Aprobados & Notables & & \\
\hline Relaciones Laborales y Ocupación & $2007-2008$ & $47,54 \%$ & $16,39 \%$ & $26,23 \%$ & $94,00 \%$ & & \\
\hline Tarde & $2008-2009$ & $36,36 \%$ & $9,09 \%$ & $27,27 \%$ & $25,00 \%$ & $2,27 \%$ & \\
\hline 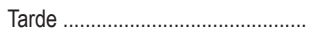 & $2009-2010$ & $34,29 \%$ & $11,43 \%$ & $20,00 \%$ & $28,57 \%$ & $5,71 \%$ & \\
\hline 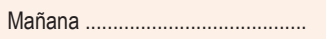 & 2010-2011 & $5,19 \%$ & $18,18 \%$ & $55,84 \%$ & $19,48 \%$ & $1,30 \%$ & $1,30 \%$ \\
\hline Tarde & 2010-2011 & $9,62 \%$ & $38,46 \%$ & $26,92 \%$ & $21,15 \%$ & $3,85 \%$ & $3,85 \%$ \\
\hline Mañana & 2011-2012 & $11,42 \%$ & $14,28 \%$ & $50,00 \%$ & $22,85 \%$ & $1,42 \%$ & $1,42 \%$ \\
\hline Tarde & $2011-2012$ & $16,66 \%$ & $16,66 \%$ & $53,70 \%$ & $12,96 \%$ & & \\
\hline 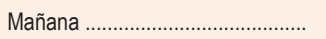 & 2012-2013 & $18,60 \%$ & $23,26 \%$ & $50,00 \%$ & $8,14 \%$ & & \\
\hline Tarde & $2012-2013$ & $18,52 \%$ & $3,70 \%$ & $51,85 \%$ & $22,22 \%$ & $3,70 \%$ & $3,70 \%$ \\
\hline Mañana & 2013-2014 & $16,18 \%$ & $19,12 \%$ & $44,12 \%$ & $20,59 \%$ & & \\
\hline Tarde & 2013-2014 & $27,27 \%$ & $4,55 \%$ & $50,00 \%$ & $18,18 \%$ & & \\
\hline Mañana & $2014-2015$ & $10,00 \%$ & $16,67 \%$ & $38,33 \%$ & $31,67 \%$ & & \\
\hline 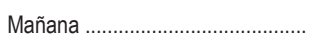 & $2015-2016$ & $8,95 \%$ & $10,44 \%$ & $58,20 \%$ & $22,38 \%$ & & \\
\hline 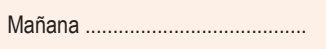 & 2016-2017 & $7,04 \%$ & $29,57 \%$ & $54,92 \%$ & $7,04 \%$ & & \\
\hline 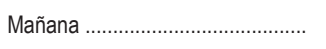 & $2017-2018$ & $4,50 \%$ & $12,12 \%$ & $62,12 \%$ & $18,18 \%$ & $3,03 \%$ & \\
\hline Media & & $16,18 \%$ & $16,39 \%$ & $50,00 \%$ & $21,15 \%$ & $3,03 \%$ & $2,56 \%$ \\
\hline
\end{tabular}

Fuente: elaboración propia (estadística sacada de las actas firmadas en la primera convocatoria).

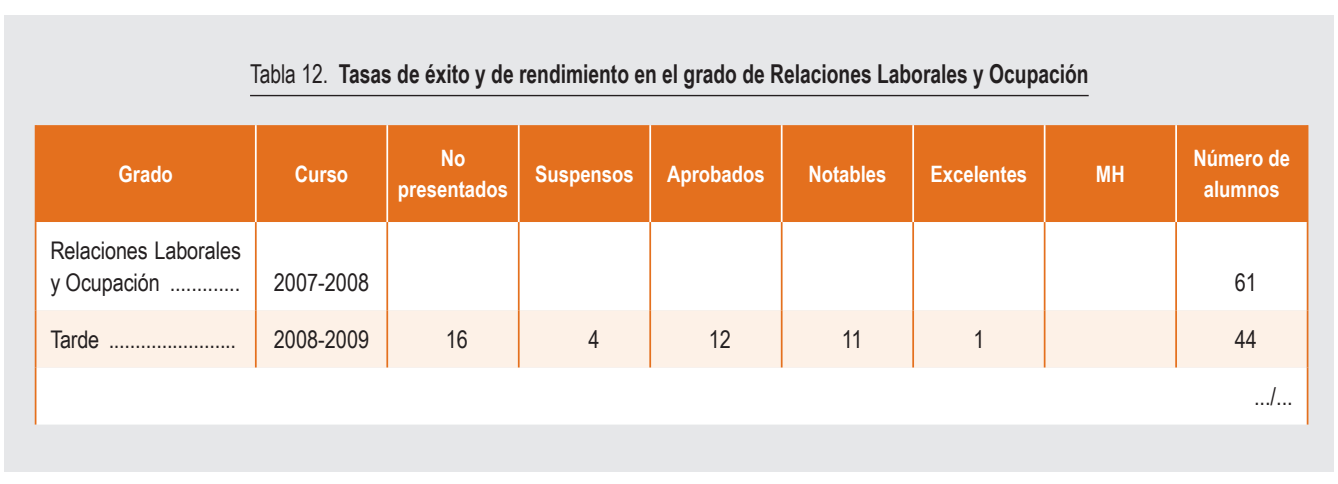


Tabla 12. Tasas de éxito y de rendimiento en el grado de Relaciones Laborales y Ocupación (cont.)

\begin{tabular}{|c|c|c|c|c|c|c|c|c|}
\hline Grado & Curso & $\begin{array}{c}\text { No } \\
\text { presentados }\end{array}$ & Suspensos & Aprobados & Notables & Excelentes & MH & $\begin{array}{l}\text { Número de } \\
\text { alumnos }\end{array}$ \\
\hline \multicolumn{9}{|l|}{$\ldots / \ldots$} \\
\hline Tarde .............................. & $2009-2010$ & 6 & 7 & 12 & 1 & 1 & & 27 \\
\hline Mañana ........................ & $2010-2011$ & 6 & 1 & 9 & 1 & & & 17 \\
\hline 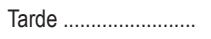 & $2010-2011$ & 9 & 9 & 29 & 7 & & & 54 \\
\hline 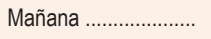 & 2011-2012 & 8 & 10 & 35 & 16 & & & 70 \\
\hline 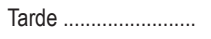 & 2011-2012 & 9 & 9 & 29 & 7 & & & 54 \\
\hline 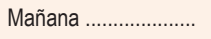 & 2012-2013 & 16 & 20 & 43 & 7 & & & 86 \\
\hline Tarde & $2012-2013$ & 5 & 1 & 14 & 6 & & 1 & 27 \\
\hline 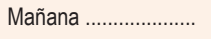 & 2013-2014 & 11 & 13 & 30 & 14 & & & 68 \\
\hline Tarde …........................ & 2013-2014 & 6 & 1 & 11 & 4 & & & 22 \\
\hline Mañana .......................... & 2014-2015 & 6 & 10 & 23 & 19 & & 2 & 60 \\
\hline 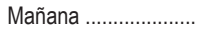 & $2015-2016$ & 8 & 16 & 26 & 15 & & & 66 \\
\hline Mañana ........................... & 2016-2017 & 5 & 21 & 39 & 5 & & & 71 \\
\hline Mañana ........................... & $2017-2018$ & 3 & 8 & 41 & 12 & 2 & & 66 \\
\hline Media ........................... & & 114 & 130 & 353 & 125 & 4 & 3 & 793 \\
\hline \multicolumn{4}{|c|}{ Tasa de éxito } & \multicolumn{5}{|c|}{ Tasa de rendimiento } \\
\hline Aprobados & \multicolumn{2}{|c|}{485} & \multirow{2}{*}{$78,86 \%$} & \multicolumn{3}{|c|}{ Aprobados .......................... } & 485 & $66,52 \%$ \\
\hline Presentados .................... & \multicolumn{2}{|l|}{615} & & \multicolumn{2}{|c|}{ Matriculados ................... } & \multicolumn{2}{|c|}{729} & \\
\hline
\end{tabular}

Fuente: elaboración propia (estadística sacada de las actas firmadas en la primera convocatoria).

\subsection{Encuestas de opinión realizadas por la URV a los alumnos en relación al profesorado}

Los resultados testados de las encuestas de opinión sobre la actividad docente del profesorado que cada año se realizan a los alumnos de la propia URV de forma institucional evidencian una valoración media de los profesores de un 6,6 sobre 7 . Se incorpora como referencia el curso 2007-2008, en el que no se impartió la metodología expuesta. Desde los cursos 20162018 la ponderación es sobre 10, alcanzando una puntuación de 9,60 sobre 10 (véase tabla 13).

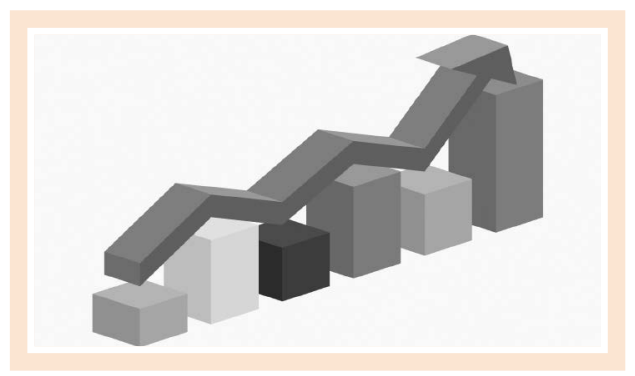




\begin{tabular}{|c|c|c|c|c|}
\hline Relaciones Laborales y Ucupacion ........... & $2008-2009$ & 6,45 & 5,01 & 5,15 \\
\hline Relaciones Laborales y Ocupación ............ & 2009-2010 & 6,74 & 5,34 & 5,22 \\
\hline Relaciones Laborales y Ocupación ............. & 2010-2011 & 6,63 & 5,32 & 5,45 \\
\hline Relaciones Laborales y Ocupación ............. & 2011-2012 & 6,22 & 5,44 & 5,46 \\
\hline Relaciones Laborales y Ocupación ............. & 2012-2013 & 6,62 & 5,46 & 5,40 \\
\hline Relaciones Laborales y Ocupación ............. & 2013-2014 & 6,85 & 5,71 & 5,49 \\
\hline Relaciones Laborales y Ocupación ............. & 2014-2015 & 6,64 & 5,63 & 5,32 \\
\hline Relaciones Laborales y Ocupación ............ & 2015-2016 & 6,89 & 5,58 & 5,50 \\
\hline Relaciones Laborales y Ocupación ............. & $2016-2017^{* *}$ & 8,64 & 7,42 & 7,33 \\
\hline Relaciones Laborales y Ocupación ............ & $2017-2018^{\star \star}$ & 8,94 & 7,79 & 7,59 \\
\hline MEDIA sobre 7 puntos & & 6,64 & 5,46 & 5,45 \\
\hline Comunicación Audiovisual ............................ & 2014-2015 & 5,92 & 5,63 & 5,51 \\
\hline 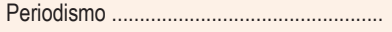 & 2014-2015 & 6,25 & 5,63 & 5,51 \\
\hline Publicidad y Relaciones Públicas ................ & 2014-2015 & 6,70 & 5,63 & 5,51 \\
\hline Comunicación Audiovisual ............................ & 2015-2016 & 6,78 & 5,58 & 5,50 \\
\hline 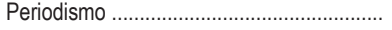 & 2015-2016 & 6,50 & 5,58 & 5,50 \\
\hline Publicidad y Relaciones Públicas ............... & 2015-2016 & 6,64 & 5,58 & 5,50 \\
\hline Comunicación Audiovisual ................................ & $2016-2017^{\star \star}$ & 8,64 & 7,42 & 7,33 \\
\hline Periodismo & $2016-2017^{* *}$ & 9,00 & 7,42 & 7,33 \\
\hline Publicidad y Relaciones Públicas ............... & $2016-2017^{* *}$ & 9,40 & 7,42 & 7,33 \\
\hline Comunicación Audiovisual ........................... & $2017-2018^{* \star}$ & 9,07 & 7,79 & 7,59 \\
\hline Periodismo & $2017-2018^{\star \star}$ & 9,33 & 7,79 & 7,59 \\
\hline Publicidad y Relaciones Públicas ................ & $2017-2018^{* *}$ & 9,60 & 7,79 & 7,59 \\
\hline
\end{tabular}

* Curso de referencia sin esta metodología.

** Valoración sobre 10 puntos. 


\subsection{Repercusión en el ámbito institucional: proyecto transversal con agentes del territorio}

\subsubsection{Instituciones y personas relevantes: participación de los agentes del territorio}

Con este método, el alumno conoce personalmente entidades, instituciones y a personajes de la vida pública, lo que contribuye notablemente a reforzar el aprendizaje de la materia expuesta y estudiada.

Gracias a esta metodología se ha logrado la participación de los agentes del territorio en la tarea docente a través de las entrevistas a un amplio abanico de personajes relevantes (superan ampliamente el centenar). Por tanto, la difusión de esta metodología de enseñanza alcanza a altas instancias institucionales, lo que es muy valorado por los propios entrevistados, cumpliendo así una función de difusión de la tarea docente de la URV (véase tabla 14).

Tabla 14. Entrevistas a personajes filmadas y visionadas en clase

\begin{tabular}{|c|c|c|c|}
\hline \multicolumn{4}{|c|}{ Personas entrevistadas } \\
\hline Nombre & Cargo & Institución & Ciudad \\
\hline
\end{tabular}

Grado de Relaciones Laborales y Ocupación

Curso 2014 y anteriores ${ }^{1}$

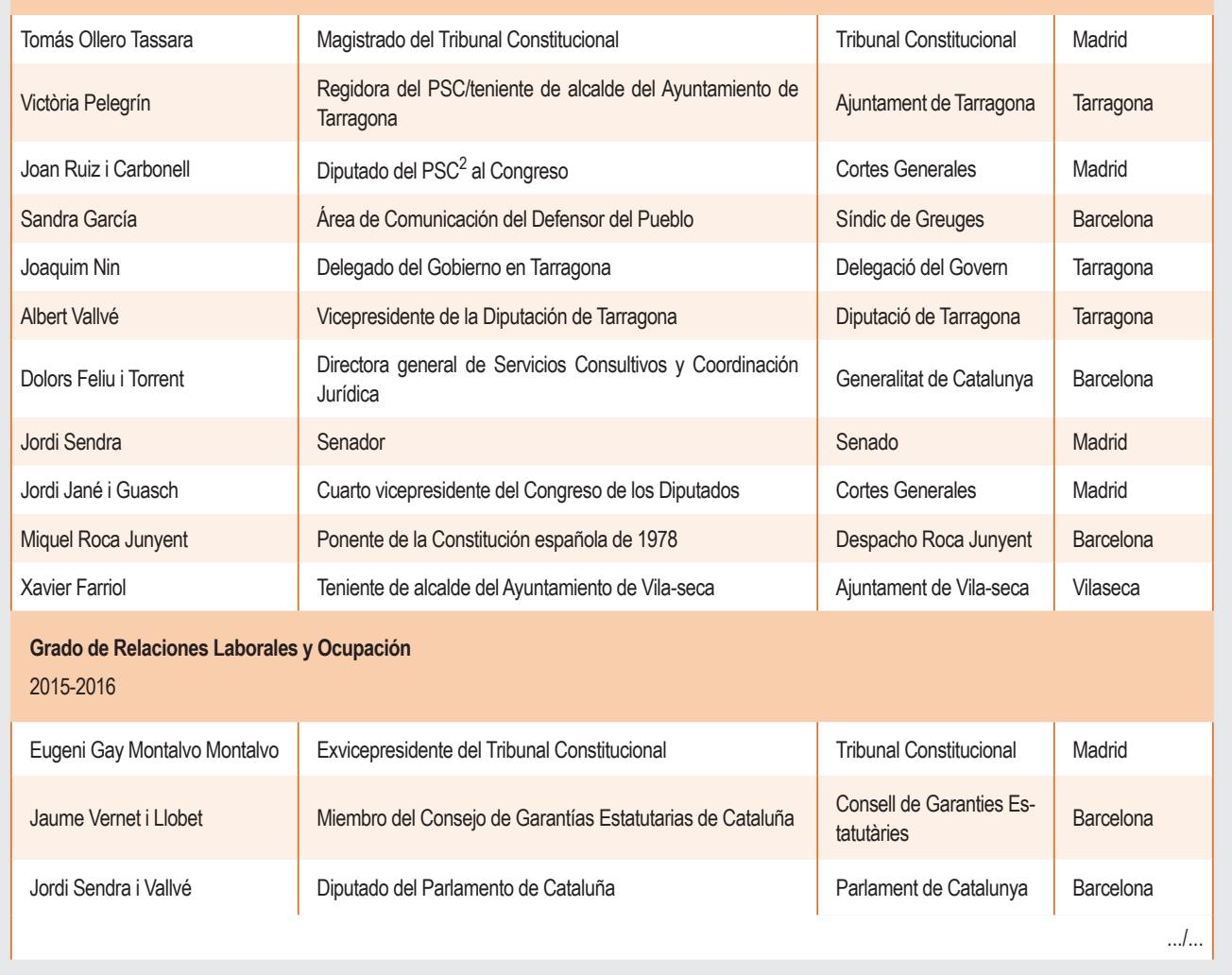


Tabla 14. Entrevistas a personajes filmadas y visionadas en clase (cont.)

\begin{tabular}{|c|c|c|c|}
\hline \multicolumn{4}{|c|}{ Personas entrevistadas } \\
\hline Nombre & Cargo & Institución & Ciudad \\
\hline \multicolumn{4}{|l|}{$\ldots / \ldots$} \\
\hline David Bonvehí & Diputado del Parlamento de Cataluña & Parlament de Catalunya & Barcelona \\
\hline Rosa Maria Ibarra & Diputada del Parlamento de Cataluña & Parlament de Catalunya & Barcelona \\
\hline Josep Maria Terricabras & Eurodiputado & Parlamento Europeo & Estrasburgo \\
\hline Jordi Carreras Llorens & Parlamento Europeo & Parlamento Europeo & Estrasburgo \\
\hline Ferran Bel & Diputado del Parlamento de Cataluña & Parlament de Catalunya & Barcelona \\
\hline Jordi Roca Mas & Diputado del Congreso & Cortes Generales & Madrid \\
\hline Alejandro Fernández & Regidor del Ayuntamiento de Tarragona & Ajuntament de Tarragona & Tarragona \\
\hline Carmen Corbacho & Área de Reformas Institucionales del PSC & PSC & Barcelona \\
\hline August Armengol & President $\mathrm{PxC}^{3}$ & Partido político & Tarragona \\
\hline Sergi de Maya & $\mathrm{ICV}^{4}$ & Partido político & Tarragona \\
\hline Martí Barberà & Diputado del Parlamento de Cataluña & Parlament de Catalunya & Barcelona \\
\hline Montserrat Duch & Profesora de Historia de la URV & URV & Tarragona \\
\hline Daniel Andreu & Alcalde de l'Aldea & Ajuntament de l'Aldea & Aldea \\
\hline Eva Parra & Jueza & Jutgats de Tarragona & Tarragona \\
\hline Josep Lluis Díez Besora & $\begin{array}{l}\text { Director de Dominio Público y Seguridad del Puerto de } \\
\text { Tarragona }\end{array}$ & Port de Tarragona & Tarragona \\
\hline Francesc Segura & Magistrada de la Sección Primera de la Audiencia de Lleida & Audiència de Lleida & Lleida \\
\hline Ernest Benach & Expresidente del Parlamento de Cataluña & Parlament de Catalunya & Barcelona \\
\hline Francesc Vallés Vives & Diputado del Congreso & Cortes Generales & Madrid \\
\hline Santiago Vidal Marsal & Exjuez y senador de $E R C^{5}$ Senado & Senat & Madrid \\
\hline Marc Sangra i Alcantarilla & Diputado del Parlamento de Cataluña & Parlament de Catalunya & Barcelona \\
\hline Jordi Miquel Sendra Vellvè & Senador de las Cortes & Cortes Generales & Madrid \\
\hline Santiago José Castellà & Profesor de Derecho Internacional de la URV & URV & Tarragona \\
\hline Susana Nieves Coll & Jefa de Prensa del Tribunal Constitucional & Tribunal Constitucional & Madrid \\
\hline Andrés Ollero & Magistrado del Tribunal Constitucional & Tribunal Constitucional & Madrid \\
\hline
\end{tabular}

Grados de Periodismo, Comunicación Audiovisual y Publicidad y Relaciones Públicas 2016-2017

\begin{tabular}{|l|l|l|l}
\hline Francesc Xavier Grau & Exrector de la URV & URV & Tarragona \\
Ramon Tremosa i Balcells & Eurodiputado de JxSí & Parlamento Europeo & Estrasburgo
\end{tabular}


Tabla 14. Entrevistas a personajes filmadas y visionadas en clase (cont.)

\begin{tabular}{|c|c|c|c|}
\hline \multicolumn{4}{|c|}{ Personas entrevistadas } \\
\hline Nombre & Cargo & Institución & Ciudad \\
\hline \multicolumn{4}{|l|}{$\ldots / \ldots$} \\
\hline Narcís Mir & Secretario de Asuntos Exteriores de la Unión Europea & Generalitat de Catalunya & Barcelona \\
\hline Dalmaci Clofent & Secretario de Asuntos Exteriores de la Unión Europea & Generalitat de Catalunya & Barcelona \\
\hline Santiago Vidal i Marsal & Exjuez, senador de ERC Senado & Senado & Madrid \\
\hline Joan Coma & Regidor & Ajuntament de Vic & Vic \\
\hline Josep Rufà & Diputado del Congreso & Cortes Generales & Madrid \\
\hline Jordi Salvador i Duch & Diputado del Congreso & Cortes Generales & Madrid \\
\hline Rubén Viñuales Elías & Regidor del Ayuntamiento de Tarragona & Ajuntament de Tarragona & Tarragona \\
\hline Rosa Maria Codines i Farré & Presidenta de Ómnium Cultural & Ómnium Cultural & Tarragona \\
\hline Raquel San & Jefa de Gabinete del Delegado de Gobierno en Tarragona & Delegació del Govern & Tarragona \\
\hline Roser Colomé & Regidora PDeCAT ${ }^{7}$ del Ayuntamiento de Vilanova i la Geltrú & Ajuntament de Vilanova & $\begin{array}{l}\text { Vilanova i la } \\
\text { Geltrú }\end{array}$ \\
\hline Aleix Auber & Alcalde de Capellades & Ajuntament de Capellades & Capellades \\
\hline Francesc Dominguez & Diputado del Parlamento de Cataluña & Parlament de Catalunya & Barcelona \\
\hline Neus Lloveras i Massana & Diputada del Parlamento de Cataluña & Parlament de Catalunya & Barcelona \\
\hline Carles Pellicer & Alcalde de Reus & Ajuntament de Reus & Reus \\
\hline Ricard Font de Rubinat & Regidor del Ayuntamiento de Reus & Ajuntament de Reus & Reus \\
\hline Cori Sisniega & Directora de instituto & Instituto de bachillerato & Reus \\
\hline Eugènia Badia & Profesora de Biología & Instituto de bachillerato & Reus \\
\hline Ester Navarreta & Profesora de Filosofía & Instituto de bachillerato & Reus \\
\hline \multicolumn{4}{|c|}{ Grado de Relaciones Laborales y Ocupación } \\
\hline \multicolumn{4}{|l|}{$2016-2017$} \\
\hline Víctor Cullell & Secretario para el Desarrollo del Autogobierno & Generalitat de Catalunya & Barcelona \\
\hline Joan Ruiz i Carbonell & Diputado del Congreso & Cortes Generales & Madrid \\
\hline Josep Poblet i Tous & Presidente de la Diputación de Tarragona & Diputació & Tarragona \\
\hline Lluís Llach & Diputado del Parlamento de Cataluña & Parlament de Catalunya & Barcelona \\
\hline Josep Acero & Regidor del Ayuntamiento de Tarragona & Ajuntament de Tarragona & Tarragona \\
\hline Carles Castillo & Diputado del Parlamento de Catalunya & Parlament de Catalunya & Barcelona \\
\hline Héctor Cabré & Abogado & Despacho de abogados & Tarragona \\
\hline Rubén Viñuales Elías & Regidor del Ayuntamiento de Tarragona & Ajuntament de Tarragona & Tarragona \\
\hline Jordi Roca Mas & Diputado del Congreso & Cortes Generales & Madrid \\
\hline
\end{tabular}


Tabla 14. Entrevistas a personajes filmadas y visionadas en clase (cont.)

\begin{tabular}{|c|c|c|c|}
\hline \multicolumn{4}{|c|}{ Personas entrevistadas } \\
\hline Nombre & Cargo & Institución & Ciudad \\
\hline \multicolumn{4}{|l|}{...$/ \ldots$} \\
\hline Josep Maria Comas & Abogado & Despacho de abogados & Reus \\
\hline Marta Valls & Abogada & Despacho de abogados & Reus \\
\hline Josep Canício i Querol & Defensor de la Comunidad Universitaria de la URV & URV & Tarragona \\
\hline Josep Rufà & Diputado del Congreso & Cortes Generales & Madrid \\
\hline Joan Laporta & Expresidente del Fútbol Club Barcelona & Fútbol Club Barcelona & Barcelona \\
\hline Laia Estrada & Regidora del Ayuntamiento de Tarragona & Ajuntament de Tarragona & Tarragona \\
\hline David Font Simon & Alcalde de Gironella & Ajuntament de Gironella & Bergadà \\
\hline
\end{tabular}

Grados de Relaciones Laborales y Ocupación, Periodismo, Comunicación Audiovisual y Publicidad y Relaciones Públicas 2017-2018

\begin{tabular}{|l|l|l|l|}
\hline José Mara Castellà Andreu & Profesor de Derecho Constitucional & $\begin{array}{l}\text { Universitat Internacional } \\
\text { de Catalunya }\end{array}$ & Barcelona \\
Xavier Arbós Marín & Profesor de Derecho Constitucional & Universitat de Barcelona \\
Hortènsia Grau Juan & Diputada del Parlamento de Cataluña & Universitat de Barcelona & Barcelona \\
Jordi Jordana & Juez de Andorra & Parlament de Catalunya & Tortosa \\
Montserrat Vilella & Diputada del Parlamento de Cataluña & Juzgados de Andorra & Andorra \\
Antonio Porta & Abogado & Parlament de Catalunya & Barcelona \\
Salvador Ferré Budesca & Teniente de alcalde & Despacho de abogados & Tarragona \\
Irene Mallol & Abogada & Ajuntament de La Canonja & Tarragona \\
Juan Borràs Tous & Autoridad Portuaria & Despacho de abogados & Tarragona \\
Josep Àngel Susín & Abogado & Port de Tarragona & Tarragona \\
Ernest Benach & Expresidente del Parlamento de Cataluña & Despacho de abogados & Tarragona \\
Jorge Soler & Diputado del Parlamento de Cataluña & Parlament de Catalunya & Barcelona \\
Ramón Luque & Parlamento Europeo & Universitat de Lleida & Lleida \\
\hline
\end{tabular}

1 Antes del 2014 no se llevaba una relación de personas entrevistadas.

2 PSC (Partido de los Socialistas de Cataluña/Partit dels Socialistes de Catalunya).

${ }^{3}$ PxC (Plataforma por Cataluña/Plataforma per Catalunya).

${ }^{4}$ ICV (Iniciativa por Cataluña Verdes/Iniciativa per Catalunya Verds).

${ }^{5}$ ERC (Esquerra Republicana de Cataluña/Esquerra Republicana de Catalunya).

6 JxSí (Juntos por el SilJunts pel Sí).

${ }^{7}$ PDeCAT (Partido Demócrata Europeo Catalán/Partit Demòcrata Europeu Català).

Fuente: elaboración propia en función de las personas entrevistadas por los alumnos. 


\subsubsection{Extensión a las Aulas de la Tercera Edad}

Algunas de las actividades y de los debates que se han ido realizando durante los cursos académicos se han hecho extensivas a las Aulas de la Tercera Edad a través de charlas. La respuesta ha sido muy positiva (un gran número de centros ha repetido estas actividades) (véase tabla 15).

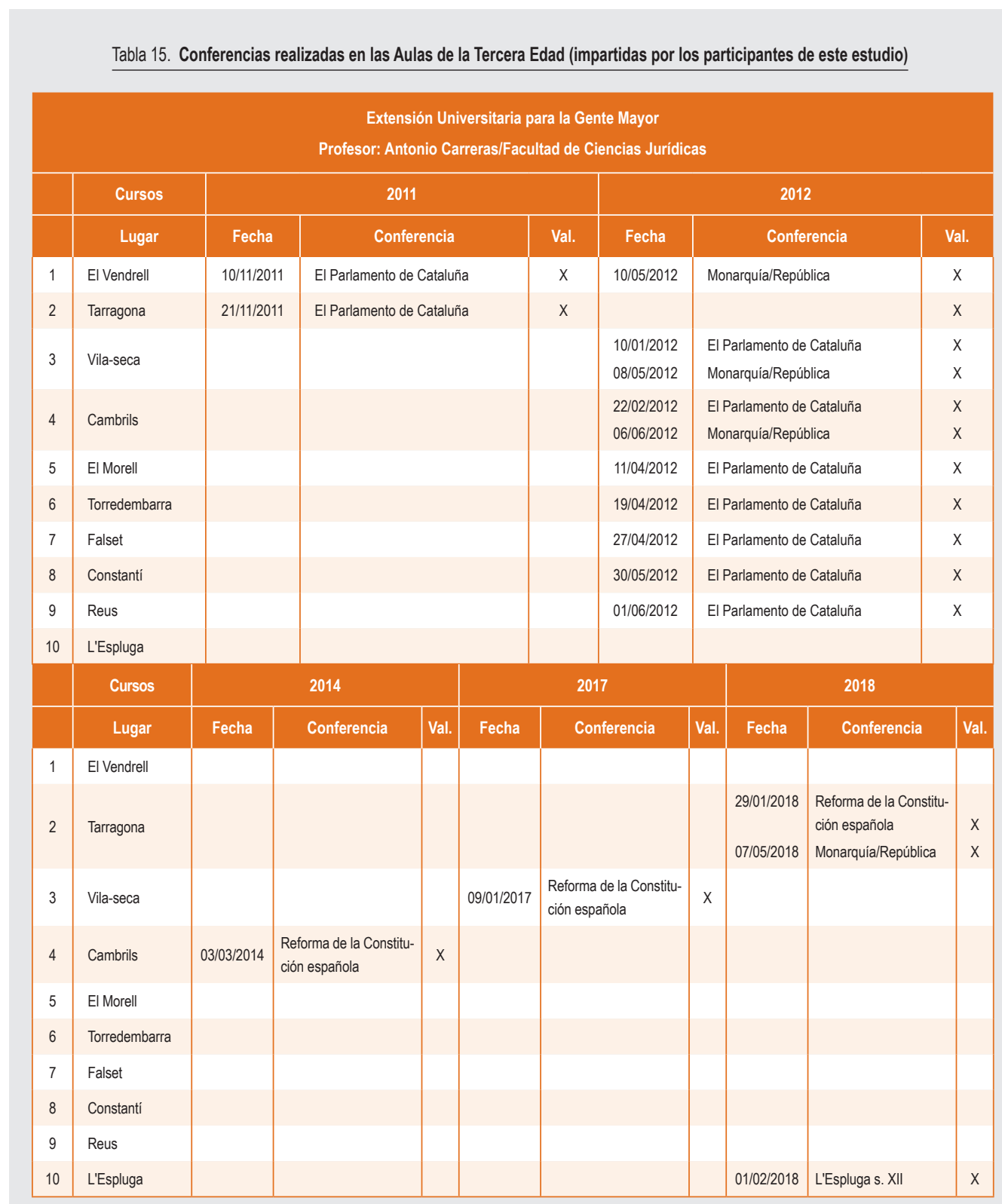

Fuente: elaboración propia en función del calendario de conferencias impartidas. 


\section{VISIBILIDAD DEL MÉTODO}

La metodología aplicada en este estudio ha sido presentada a través de diversas comunicaciones y ponencias en congresos internacionales y en jornadas, con sus correspondientes publicaciones:

- Metodologies docents per estimular l'interès per una matèria, VII Congrés Internacional de Docència Universitària i Innovació: La Universitat, una Institució de la Societat, Barcelona, 4, 5 y 6 de julio de 2012. ISBN: 978-84-695-4073-2. (Comunicación).

- Metodologías docentes para estimular el interés por una materia con ayuda de las TIC, III Jornada sobre Docencia del Derecho y TIC de la Universitat Oberta de Catalunya, Barcelona 2012, pp. 43-55. (Ponencia).

- Universitat i empresa. Camins divergents o convergents?, Congrés Internacional de Docència Universitària i Innovació, Tarragona, 2, 3 y 4 de julio de 2014. ISSN: 2385-6203. (Comunicación).

- La implicació com a mètode docent, I Jornada sobre Docència Virtual i Experiències d'Innovació Docent, Grup d'Innovació Docent Facultat de Ciències Jurídiques de la URV, Tarragona, 18 de julio de 2014, pp. 167-184. ISBN: 978-84-15663-38-6. (Ponencia).

\section{OBJETIVOS TRANSVERSALES}

Los objetivos transversales que se han logrado con este método se podrian resumir en los que se enumeran a continuación:

\section{- Adecuación a los planes estratégicos de la URV.} Con la implicación de las instituciones, se han conseguido generar interacciones eficientes y de beneficio mutuo con los agentes territoriales, así como con las Aulas de Extensión Universitaria para la Gente Mayor, tal y como especifica el Plan Estratégico de la Tercera Misión de la URV. Además se ha logrado el compromiso con los valores, también especificado en la Tercera Misión.

- Mejora e innovación en el ámbito disciplinario al que se ha aplicado el proyecto. La motivación y el interés de los estudiantes de los grados de Periodismo, Comunicación Audiovisual y Publicidad y Relaciones Públicas de la Facultad de Letras, así como
- Docencia virtual y experiencias de innovación docente (Milenka Villca y Antoni Carreras [Coords.]), I Jornada sobre Docència Virtual i Experiències d'Innovació Docent, Barcelona, 18 de julio de 2014, 229 pp., Huygens Editorial, 2014. ISBN: 97884-15663-38-6.

- Docencia virtual y experiencias de innovación docente entornos b-learning i e-learning (Milenka Villca y Antonio Carreras [Coords.]), II Jornada sobre Docència Virtual i Experiències d'Innovació Docent: Entorns B-learning i E-learning, Barcelona, 11 de junio de 2015, Huygens Editorial. ISBN: 978-8415663-49-2.

- Diagnosi sobre l'aplicació dels sistemes d'avaluació continuada en els ensenyaments de grau. L'exemple de la Facultat de Ciències Jurídiques de la Universitat Rovira i Virgili (Héctor Simón, Antonio Carreras y Blanca Deusdad), V Congreso Internacional UNIVEST'15: Els Reptes de Millorar I'Avaluació, Gerona, 9 y 10 de julio de 2015, pp. 480-487, Universitat de Girona. ISBN: 978-84-8458-453-7. (Comunicación). la de los estudiantes del grado de Relaciones Laborales y Ocupación de la Facultad de Ciencias Jurídicas en relación a la materia Derecho Constitucional era muy bajo. A las clases magistrales tradicionales de esta materia les faltaba un replanteamiento que consiguiera motivar a los estudiantes; hito que se ha logrado con este método docente.

- Aplicable a otras materias. Este método de colaboración con agentes externos a la universidad puede ser utilizado en diversas materias y en distintos ámbitos empresariales o institucionales (por ejemplo, en derecho mercantil, financiero o tributario, en empresas privadas; en derecho administrativo, en los ayuntamientos; en derecho procesal, en los juzgados; etc.). Del mismo modo, también puede ser aplicado por otras disciplinas, como en Económicas, Ingeniería, Arquitectura, etc., destacando la transversalidad del método como uno de sus objetivos aplicables. 


\section{- Orientado a la mejora de la empleabilidad del es-} tudiante. La constante preocupación de este método docente por potenciar los valores y los principios de comportamiento incide en la formación de los estudiantes como personas. En consecuencia, los alumnos reciben unas bases de comportamiento ético que su incorporación al mundo laboral les exigirá (responsabilidad, honradez, confianza, actitud, etcétera).

- Visibilidad del método. El impacto mediático producido por las entidades y por los agentes políticos e institucionales que han colaborado con los alumnos se ha notado en el número de entrevistas conseguidas y en el eco social que se ha logrado. No olvidemos, además, que este método ha sido presentado en diversos congresos y jornadas, como ha quedado reflejado.

\section{CONCLUSIONES}

Durante 11 años hemos venido aplicando este método docente sobre un colectivo que supera los 1.500 estudiantes, lo que nos ha permitido contar con una rigurosa y fiable base de datos para poder extraer unos resultados altamente satisfactorios y constatar la bondad del mismo. Esto nos proporciona la llave de acceso para innovar con nuevas tecnologías y abrir otras líneas de mejora docente a través de la tecnología digital. Nuevos retos que implementaremos en un futuro próximo con aplicaciones para dispositivos móviles creados ex novo para la docencia de la URV.

Además, todo lo expuesto nos permite afirmar que con este método se consiguen alcanzar unas altas cotas de motivación, interés y participación de los alumnos en la materia, objetivo estratégico básico para alcanzar la mayoría de las competencias planteadas inicialmente y mejorar e innovar el ámbito disciplinario al que se aplica (Derecho Constitucional), así como una notable participación y colaboración institucional y de personalidades públicas de relevancia, lo que contribuye a difundir la labor docente de nuestra universidad a la sociedad y cumplir de este modo parte del plan estratégico de la URV.
Este método, aplicado a la disciplina de Derecho Constitucional, puede ser exportado a otras disciplinas que permitan contrastar la teoría de la materia con la realidad de la misma en la sociedad, en la empresa, etc. Solo hay que poner un poco de imaginación y adaptarlo a las realidades de otras asignaturas; por lo tanto, es un método transversal y multidisciplinar.

Este método no solo despierta el interés del alumnado por la materia, sino que crea la condición indispensable para trabajar la importancia de los valores sociales y los principios individuales de comportamiento, que son tan esenciales para nuestra democracia y para la formación de futuros profesionales que nutrirán la sociedad, alcanzando así competencias nucleares de capital importancia.

Este método aporta un impacto social remarcable de la labor de la universidad en su territorio.

Como dice Bain, el aprendizaje tiene poco sentido si no es capaz de influir de forma duradera e importante en la manera de pensar, de actuar y de sentir del alumno.

\section{BIBLIOGRAFÍA}

Bain, K. (2007). Lo que hacen los mejores profesores universitarios. Valencia: Universitat de València.

García-Valcárcel Muñoz Repiso, A. (Coord.) (2002). Didàctica universitaria. Madrid: La Muralla.

Hannan, A. y Silver, H. (2003). Innovar en la universidad. Madrid: Narcea.

Imbernon, F. y Medina, J. L. (2005). Estratègies metodològiques de participació de l'alumnat. Barcelona: ICE.

Imbernon, F. (2007). Millorar l'ensenyament i l'aprenentatge a la universitat. Quaderns de Docència Universitària, 14.

Villardón, L. (2006). Evaluación del aprendizaje para promover el desarrollo de competencias. Educatio Siglo $X X I, 24,57-76$.

Yániz Álvarez de Eulate, C. (2006). Planificar la enseñanza universitaria para el desarrollo de competencias. Educatio Siglo XXI, 24, 17-34. 


\section{Relación de ciclos formativos de grado superior para cursar grados en la UDIMA}

La Universidad a Distancia de Madrid (UDIMA) tiene aprobado el reconocimiento de los ciclos formativos de grado superior para cursar las carreras universitarias indicadas por la Consejería de Educación de la Comunidad de Madrid:

\section{Para el Grado en Ingeniería de Organización industrial}

- Administración y Finanzas.

- Administración de Sistemas Informáticos.

- Automatización y Robótica Industrial.

- Automoción.

- Construcciones Metálicas.

- Desarrollo de Productos Electrónicos.

- Desarrollo de Proyectos Mecánicos.

- Diseño en Fabricación Mecánica.

- Instalaciones Electrotécnicas.

- Mantenimiento Aeromecánico.

- Mantenimiento de Equipo Industrial.

- Mantenimiento y Montaje de Instalaciones de Edificio y Proceso.

- Mantenimiento de Instalaciones Térmicas y de Fluidos.

- Mecatrónica Industrial.

- Industrias de Proceso Químico.

- Producción por Mecanizado.

- Programación de la Producción en Fabricación Mecánica.

- Química Industrial.

- Sistemas Electrotécnicos y Automatizados.

- Sistemas de Regulación y Control Automáticos.

- Sistemas de Telecomunicaciones e Informáticos.
Para el Grado en Ingeniería de Tecnologías y Servicios de Telecomunicación

- Administración de Sistemas Informáticos.

- Automatización y Robótica Industrial.

- Desarrollo de Aplicaciones Informáticas.

- Desarrollo de Aplicaciones Multiplataforma.

- Desarrollo de Aplicaciones Web.

- Desarrollo de Productos Electrónicos.

- Instalaciones Electrotécnicas.

- Mantenimiento Electrónico.

- Sistemas Electrotécnicos y Automatizados.

- Sistemas de Regulación y Control Automáticos.

- Sistemas de Telecomunicaciones e Informáticos

Para los Grados en Derecho o en Ciencias del Trabajo, Relaciones Laborales y Recursos Humanos

- Administración y Finanzas.

- Asistencia a la Dirección.

- Secretariado. 


\section{para cursar grados en la UDIMA}

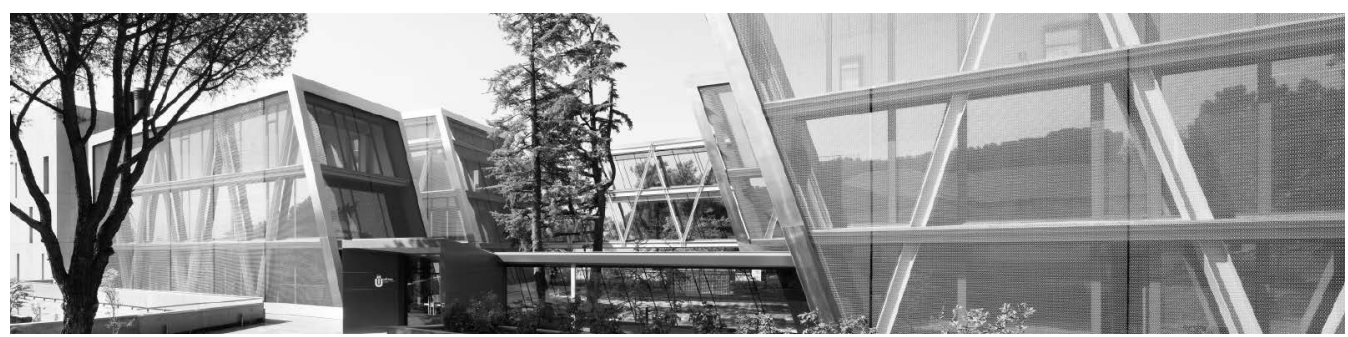

\section{< > Para el Grado en Ingeniería Informática}

- Administración de Sistemas Informáticos.

- Automatización y Robótica Industrial.

- Desarrollo de Aplicaciones Informáticas.

- Desarrollo de Aplicaciones Multiplataforma.

- Desarrollo de Aplicaciones Web.

- Sistemas de Telecomunicaciones e Informáticos.

\section{Para los Grados en Administración y Dirección de Empresas o en Economía}

- Administración y Finanzas.

- Asistencia a la Dirección.

- Comercio Internacional.

- Gestión Comercial y Marketing.

- Marketing y Publicidad.

- Secretariado.

- Transporte y Logística.

\section{Para el Grado en Marketing}

- Administración y Finanzas.

- Comercio Internacional.
- Gestión Comercial y Marketing.

- Gestión de Alojamientos Turísticos.

- Gestión de Ventas y Espacios Comerciales.

- Marketing y Publicidad.

- Transporte y Logística.

Para los Grados en Magisterio de Educación Infantil y de Educación Primaria

- Animación de Actividades Físicas y Deportivas.

- Educación Infantil.

- Integración Social.

- Animación Sociocultural y Turística.

\section{Para el Grado en Empresas y} Actividades Turísticas

- Gestión Comercial y Marketing.

- Gestión de Ventas y Espacios Comerciales.

- Gestión de Alojamientos Turísticos.

- Agencias de Viajes y Gestión de Eventos.

- Guía, Información y Asistencias Turísticas. 


\section{5 Servicio de Bolsa de Trabajo y Orientación de Prácticas Externas \\ Apoyo permanente en el desarrollo profesional a los más de 500.000 alumnos que han pasado por el CEF.- y la UDIMA}

El EF.- y la UDIMA ponen a disposición de los estudiantes diversos servicios de asesoramiento y formación para apoyar al alumno en su desarrollo académico y profesional. Es muy importante que el estudiante conozca la realidad laboral de su grado o máster, por lo que para finalizar sus estudios universitarios resulta imprescindible la realización de prácticas externas. Este servicio de Bolsa de Trabajo y Orientación de Prácticas Externas ofrece a las empresas y entidades educativas las herramientas necesarias para satisfacer sus necesidades en los procesos de selección de profesionales cualificados.

Desde nuestros orígenes hemos tenido como lema «formación para el empleo», por ello consideramos este servicio como un pilar fundamental para nuestras acciones formativas, pues todas van dirigidas a buscar empleo para nuestros alumnos, a la mejora del que ya tienen o a conseguir su consolidación.
Desde el Servicio de Bolsa de Trabajo y Orientación de Prácticas Externas agradecemos tanto a las empresas y entidades educativas como a los alumnos y antiguos alumnos que utilicen este servicio como fuente de reclutamiento para los procesos de selección en todas las áreas que se imparten en el EFF.- y en la UDIMA.

Este servicio es GRATUITO tanto para los estudiantes como para las entidades educativas.

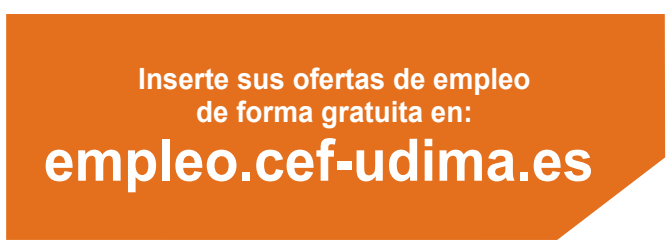

